\title{
Glutamatergic Modulation of Cerebellar Interneuron Activity Is Mediated by an Enhancement of GABA Release and Requires Protein Kinase A/RIM1 $\alpha$ Signaling
}

\author{
Philippe M. Lachamp, Yu Liu, and Siqiong June Liu \\ Department of Biology, Pennsylvania State University, State College, Pennsylvania 16802
}

\begin{abstract}
Information processing in the CNS is controlled by the activity of neuronal networks composed of principal neurons and interneurons. Activity-dependent modification of synaptic transmission onto principal neurons is well studied, but little is known about the modulation of inhibitory transmission between interneurons. However, synaptic plasticity at this level has clear implications for the generation of synchronized activity. We investigated the molecular mechanism(s) and functional consequences of an activity-induced lasting increase in GABA release that occurs between inhibitory interneurons (stellate cells) in the cerebellum. Using whole-cell recording and cerebellar slices, we found that stimulation of glutamatergic inputs (parallel fibers) with a physiological-like pattern of activity triggered a lasting increase in GABA release from stellate cells. This activity also potentiated inhibitory transmission between synaptically connected interneurons. Extracellular recording revealed that the enhanced inhibitory transmission reduced the firing frequency and altered the pattern of action potential activity in stellate cells. The induction of the sustained increase in GABA release required activation of NMDA receptors. Using pharmacological and genetic approaches, we found that presynaptic cAMP/PKA (protein kinase A) signaling and RIM1 $\alpha$, an active zone protein, is the critical pathway that is required for the lasting enhancement of GABA release. Thus, a common mechanism can underlie presynaptic plasticity of both excitatory and inhibitory transmission. This activity-dependent regulation of synaptic transmission between inhibitory interneurons may serve as an important mechanism for interneuronal network plasticity.
\end{abstract}

Key words: inhibitory transmission; RIM1 $\alpha$; long-term potentiation; PKA; cerebellum; interneurons

\section{Introduction}

Glutamate has emerged as a major regulator of inhibitory synaptic transmission. Through the activation of NMDA receptors (NMDARs), glutamate paradoxically enhances GABA release from inhibitory neurons in several brain regions (Gaiarsa et al., 2002; Liu and Lachamp, 2006; Nugent et al., 2007), producing a long-lasting change in inhibitory synaptic transmission. Inhibitory neurons innervate principal neurons and connect to other interneurons to form inhibitory networks. Thus, a sustained increase in GABA release can suppress the activity of principal neurons and modulate the activity of inhibitory networks, leading to global changes in the activity of neuronal circuits.

NMDARs are present in the presynaptic terminals of GABAergic neurons (Paquet and Smith, 2000; Duguid and Smart, 2004; Fiszman et al., 2005). Recent studies reveal that activation of presynaptic NMDARs can induce lasting changes in GABA release from inhibitory neurons in the visual system (Lien

Received May 24, 2008; revised 0ct. 29, 2008; accepted Nov. 28, 2008.

This work was supported by National Science Foundation Grant IBN-0344559 and National Institutes of Health Grant NS58867 (S.J.L.). We thank Dr. Thomas Südhof (University of Texas Southwestern Medical Center, Dallas, TX) for kindly providing the RIM1 $\alpha$ knock-out mouse. We thank Dr. Matthew Whim and laroslav Savtchouk for helpful discussions and comments on this manuscript, and Dr. Bernhard Luscher for advice on molecular biology.

Correspondence should be addressed to Dr. Siqiong June Liu, Department of Biology, 419 Mueller Laboratory, Pennsylvania State University, State College, PA 16802. E-mail: sjl16@psu.edu.

D01:10.1523/JNEUROSCI.2354-08.2009

Copyright $\odot 2009$ Society for Neuroscience $\quad$ 0270-6474/09/290381-12\$15.00/0 et al., 2006). In the cerebellum, stimulation of glutamatergic parallel fiber (PF) inputs triggers a sustained enhancement of GABA release from stellate cells [inhibitory long-term potentiation (ILTP)]. This effect requires the activation of presynaptic NMDARs (Liu and Lachamp, 2006).

Cerebellar stellate cells are connected to each other via GABAergic synapses. They form inhibitory networks and fire action potentials synchronously (Mann-Metzer and Yarom, 1999). Because action potential frequency and pattern in stellate cells are strongly influenced by inhibitory inputs (Häusser and Clark, 1997), a lasting enhancement of GABA release from stellate cells may have a profound impact on the synchronized activity of inhibitory networks within the cerebellum.

Given the importance of glutamatergic modulation of GABA release, it is critical to understand the molecular events that link NMDAR activation to enhanced GABA release. The induction of I-LTP requires calcium entry through presynaptic NMDARs (Liu and Lachamp, 2006). This can lead to an increase in the production of cAMP via $\mathrm{Ca}^{2+}$-stimulated adenylyl cyclase and thus protein kinase A (PKA) activation (Storm et al., 1998). PKA phosphorylates a presynaptic active zone protein, $\operatorname{RIM} 1 \alpha$, and promotes a sustained increase in glutamate release (Lonart et al., 2003). RIM1 $\alpha$ is also required for presynaptic long-term potentiation (LTP) at excitatory synapses (Castillo et al., 2002). Deletion of RIM1 $\alpha$ enhances presynaptic long-term depression (LTD) at the mossy fiber glutamatergic synapse, but abolishes 
presynaptic LTD of inhibitory transmission (Chevaleyre et al., 2007). However, whether PKA and RIM1 $\alpha$ are involved in I-LTP is unknown.

Here, we demonstrate that a physiologically relevant stimulation of glutamatergic inputs evokes a lasting increase in GABA release at inhibitory synapses between stellate cells. One functional consequence of this effect is a marked alteration in the firing pattern in stellate cells. We find that NMDAR activation enhances GABA release via a presynaptic cAMP/PKA signaling pathway, and deletion of RIM1 $\alpha$ abolishes I-LTP. Thus, the cAMP/PKA/RIM1 $\alpha$ signaling pathway is a general mechanism that underlies the long-term modulation of transmitter release at both excitatory and inhibitory synapses. Because strong inhibitory transmission between GABAergic neurons is needed for the generation of synchronized network oscillations (Bartos et al., 2007; Middleton et al., 2008), an implication of our findings is that glutamate can regulate the activity of an interneuron network via an enhancement of GABA release.

\section{Materials and Methods}

Slice preparation

Saggital and horizontal cerebellar slices $(250-350 \mu \mathrm{m})$ from postnatal day 18 (P18) to P23 C57BL/6J, RIM1 $\alpha^{-1-}$ or wild-type mice were obtained as previously described (Liu and Cull-Candy, 2000; Liu and CullCandy, 2005). Briefly, mice were decapitated and the cerebellum was quickly removed. Slices were cut with a Leica VT1000S vibrating microslicer in an ice-cold artificial CSF (ACSF) containing the following (in mM): $125 \mathrm{NaCl}, 2.5 \mathrm{KCl}, 1 \mathrm{CaCl}_{2}, 7 \mathrm{MgCl}_{2}, 26 \mathrm{NaHCO}_{3}, 1.25 \mathrm{NaH}_{2} \mathrm{PO}_{4}$, 25 glucose, and 1 kynurenic acid. Slices were then allowed to recover for $1 \mathrm{~h}$ in a similar saline containing $2 \mathrm{mM} \mathrm{CaCl}_{2}, 1 \mathrm{mM} \mathrm{MgCl}_{2}$ in the absence of kynurenic acid at room temperature and bubbled with $95 \%$ $\mathrm{O}_{2} / 5 \% \mathrm{CO}_{2}$.

\section{Electrophysiology}

Whole-cell voltage and current-clamp recordings were made with Multiclamp 700A and Axopatch 200B amplifiers (Molecular Devices). The extracellular solution (in mM: $125 \mathrm{NaCl}, 2.5 \mathrm{KCl}, 2 \mathrm{CaCl}_{2}, 1 \mathrm{MgCl}_{2}, 1.25$ $\mathrm{NaH}_{2} \mathrm{PO}_{4}, 26 \mathrm{NaHCO}_{3}$, and 25 glucose, $\mathrm{pH} 7.4$ ) was continuously bubbled with $95 \% \mathrm{O}_{2}$ and $5 \% \mathrm{CO}_{2}$. Electrode resistance was 6-8 M $\Omega$. Inhibitory synaptic currents were filtered at $2 \mathrm{kHz}$ and digitized at $10 \mathrm{kHz}$. Stellate cells were identified by their location in the outer two-thirds of the molecular layer and by their ability to fire spontaneous action potentials in the cell-attached configuration. All recordings were performed at $32-36^{\circ} \mathrm{C}$, unless otherwise noted.

\section{Evoked IPSCs and evoked EPSCs}

Currents were evoked with a glass monopolar stimulating electrode placed at least $80 \mu \mathrm{m}$ from the recording pipette to avoid direct stimulation of the postsynaptic neuron. Depolarizing pulses were delivered with a Digitimer DS2A Mk. II stimulator (Digitimer) at $0.3 \mathrm{~Hz}$. The strength and duration of the stimulating pulses were adjusted to obtain monosynaptic responses. Typical stimulation strength and duration were $2-10 \mathrm{~V}$ and 120-200 $\mu$ s, respectively. Electrodes were filled with a pipette solution (in mM: 120 Cs-acetate, $2.9 \mathrm{MgCl}_{2}, 0.1 \mathrm{CaCl}_{2}, 10 \mathrm{HEPES}, 10$ EGTA, $4 \mathrm{Na}-\mathrm{ATP}$, and $0.4 \mathrm{Na}-\mathrm{GTP}, \mathrm{pH} 7.3$ ), which set the reversal potential for $\mathrm{Cl}^{-}$to $-81 \mathrm{mV}$. Evoked IPSCs (eIPSCs) were recorded at $-30 \mathrm{mV}$ and visualized as outward currents. Evoked EPSCs (eEPSCs) were recorded at $-60 \mathrm{mV}$ and visualized as inward currents. In some experiments, NMDAR-mediated currents were evoked by a train of PF stimulation (four stimuli at $100 \mathrm{~Hz}$ ) and recorded at $+40 \mathrm{mV}$ in the presence of glycine $(20 \mu \mathrm{M}), \mathrm{GABA}_{\mathrm{A}}$ receptor blockers, picrotoxin (PTX) $(50 \mu \mathrm{M})$ or 6-imino-3-(4-methoxyphenyl)-1(6H)-pyridazinebutanoic acid hydrobromide (SR95531) $(20 \mu \mathrm{M})$, an AMPA receptor (AMPAR) blocker, 1,2,3,4-tetrahydro-6-nitro-2,3-dioxo-benzo[f] quinoxaline-7-sulfonamide (NBQX) $(5 \mu \mathrm{M})$, and a glycine receptor blocker, strychnine $(1 \mu \mathrm{M})$. Series resistance was monitored throughout the experiment, which was terminated if that parameter changed by $>20 \%$.

\section{Miniature IPSCs}

Neurons were voltage clamped at $-30 \mathrm{mV}$. Synaptic currents were recorded in the presence of TTX $(0.5 \mu \mathrm{M})$ using the Cs-based internal solution described above. TTX was washed out for $20 \mathrm{~min}$ before I-LTP induction by parallel fiber stimulation. A K-based pipette solution (in mM: $135 \mathrm{KCl}, 4.6 \mathrm{MgCl}_{2}, 0.1 \mathrm{CaCl}_{2}, 10$ HEPES, 10 EGTA, $4 \mathrm{Na}-\mathrm{ATP}$, and $0.4 \mathrm{Na}-\mathrm{GTP}, \mathrm{pH} 7.4$ ) was used in a few experiments conducted at room temperature $\left(21-23^{\circ} \mathrm{C}\right)$. In these experiments, neurons were clamped at $-70 \mathrm{mV}$ and miniature IPSCs (mIPSCs) were seen as inward currents.

\section{Action potential recordings}

Action potentials were recorded in whole-cell current-clamp mode and were evoked by means of a ramp depolarization (rise time of $0.25 \mathrm{~ms}$ and falling phase of $100 \mathrm{~ms}$ ), to mimic NMDAR-mediated synaptic currents. These experiments were performed in an extracellular solution (ACSF) containing $1 \mathrm{~mm}$ kynurenic acid and $100 \mu \mathrm{M}$ PTX. To determine the frequency and pattern of action potential firing in stellate cells, action potentials were recorded extracellularly using the cell-attached configuration. The loose patch resistance was $<100 \mathrm{M} \Omega$ and recordings were made using the slow current-clamp mode of the amplifier.

\section{I-LTP induction}

I-LTP was induced by parallel fiber stimulation that mimicked physiological stimulation or by a brief application of NMDA and glycine (chemical induction).

PF stimulation. A parallel bipolar electrode (150 $\mu \mathrm{m}$ spacing) was placed across the molecular layer $\sim 200 \mu \mathrm{m}$ from the recording electrode and was used to stimulate PFs. The stimulus intensity ranged from 5 to 50 $\mathrm{V}$ with a duration of $0.2 \mathrm{~ms}$. The stimulation protocol consisted of a train of four pulses at $100 \mathrm{~Hz}$, which was repeated 5 or 15 times at $1 \mathrm{~Hz}$. The cell was voltage clamped at $-60 \mathrm{mV}$ during stimulation.

Chemical induction. ACSF that contained 15-30 $\mu \mathrm{M}$ NMDA and $20 \mu \mathrm{M}$ glycine was superfused for $5 \mathrm{~min}$ at room temperature or for $30 \mathrm{~s}$ at $32-36^{\circ} \mathrm{C}$. During NMDA/glycine application, the postsynaptic cell was voltage clamped at $-60 \mathrm{mV}$. NBQX $(5 \mu \mathrm{M})$ and strychnine $(1 \mu \mathrm{M})$ were present throughout the experiment. The experiments in which mIPSCs were monitored before and after application of NMDA/glycine were performed at room temperature. Experiments in which NMDA/glycine application was used to induce I-LTP of evoked IPSCs were conducted at $32-36^{\circ} \mathrm{C}$.

\section{Data analysis}

Average eIPSCs or eEPSCs were constructed from at least 50 sweeps. Each mean paired-pulse response was obtained from at least $50-70$ events. Events with a nontypical shape and latency were rejected (these are likely to be spontaneous IPSCs). The paired-pulse ratio (PPR) was calculated as the amplitude ratio of the average IPSC $_{2}$ to average IPSC $_{1}$. The coefficient of variation (CV) of synaptic currents was calculated from the peak amplitude of at least 70 events. Miniature IPSCs were identified using the template detection feature of Clampfit (version 9.2). A template was constructed from $\sim 500$ mIPSCs that were manually selected from a typical recording. The template accuracy was checked using the manual event selection mode. The detection threshold was adjusted such that both false-positive and false-negative events detected by the template represented $\sim 5 \%$ of the total number of mIPSCs (false positive, $5.5 \pm 1.1 \%$; false negative, $4.6 \pm 0.5 \% ; n=5$ ). Significant difference was assessed using a two-tailed Student's $t$ test. Data are presented as mean \pm SEM.

\section{Genotyping}

RIM1 $\alpha^{-1-}$ mice were generated from mating heterozygous male and female mice and identified by genotyping tail DNA, as described previously (Schoch et al., 2002). Briefly, tail clips were taken from P15 mice and digested overnight at $37^{\circ} \mathrm{C}$ in $400 \mu \mathrm{l}$ of SNET buffer containing the following: $20 \mathrm{~mm}$ Tris, pH 8, $5 \mathrm{~mm} \mathrm{Na}_{2}$ EDTA, $400 \mathrm{~mm} \mathrm{NaCl}, 1 \%$ SDS, and proteinase $\mathrm{K}(0.5 \mathrm{mg} / \mathrm{ml})$. For genotyping, we used the following primers: wild type, CAACTGTGGCTGTGCACACTTGCCG and CGTGCATACTCCACTGATCTCTCCC, product size, $0.26 \mathrm{~kb}$; RIM1 $\alpha \mathrm{mu}-$ tant, CAACTGTGGCTGTGCACACTTGCCG and GAGCGCGCGCG- 
A
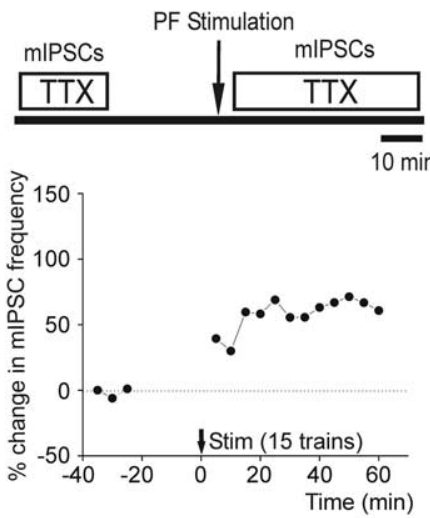

C

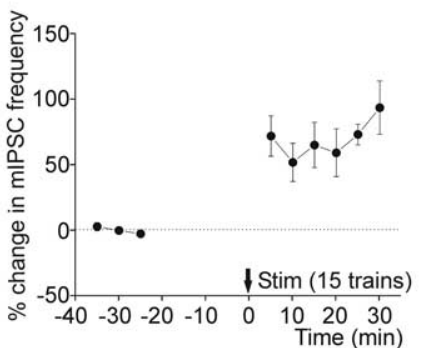

B

Before stimulation

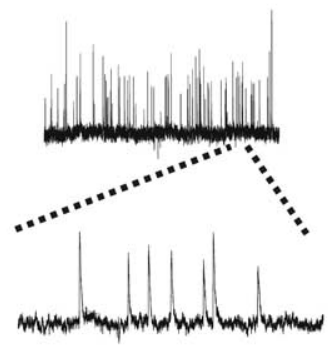

D

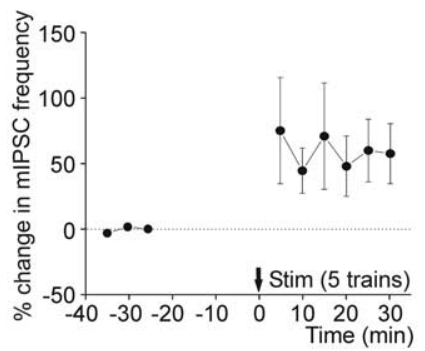

30 min after stimulation

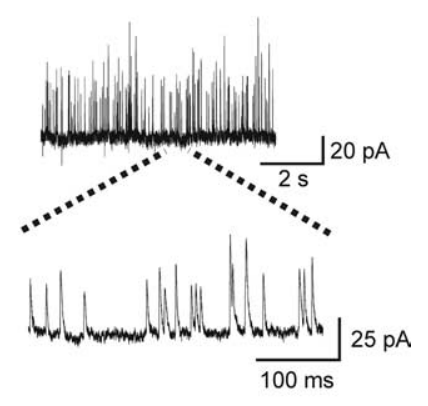

$E$

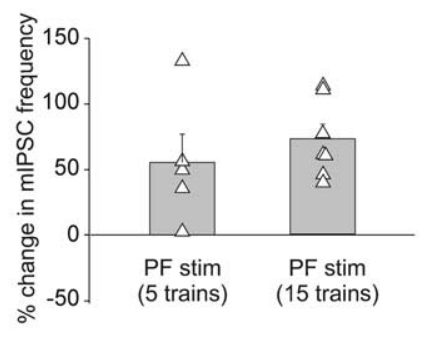

Figure 1. Physiologically relevant burst stimulation of parallel fibers induces a lasting increase in spontaneous GABA release from stellate cells. $\boldsymbol{A}$, Schematic of the experimental protocol (top) and $\mathrm{mIPSC}$ frequency time course before and after stimulation recorded in a postsynaptic stellate cell (bottom). $\boldsymbol{B}, \mathrm{mIPSC}$ in a stellate cell before and after PF stimulation. The bottom traces are enlargements of regions designated by the dashed lines. $\boldsymbol{C}, \boldsymbol{D}$, Time course of mIPSC frequency recorded after $15(n=7)$ and 5 trains $(n=5)$ of PF stimulation. $\boldsymbol{E}$, Summary data. Individual cells are shown as open triangles, and the bars represent the average value for each group. Error bars indicate SEM.

GCGGAGTTGTTGAC, product size, $0.30 \mathrm{~kb}$. These were run as separate reactions. The PCR products were visualized on a $1.75 \%$ agarose gel.

PTX, TTX, kynurenic acid, D(-)-3-(2-carboxypiperazine-4-yl)propyl-1-phosphonic acid (CPP), 7-chloro-kynurenic acid, $\alpha$-methyl-4carboxyphenylglycine (MCPG), ( \pm )-1-[2,3-(dihydro-7-methyl-1 Hinden-4-yl)oxy]-3-[(1-methylethyl)amino]-2-butanol hydrochloride (ICI 118,551), (9R,10S,12S)-2,3,9,10,11,12-hexahydro-10-hydroxy-9methyl-1-oxo-9, 12-epoxy-1 H-diindolo[1,2,3-fg:3', $2^{\prime}, 1^{\prime}$-kl]pyrrolo[3,4-i] [1,6]benzodiazocine-10-carboxylic acid, hexyl ester (KT5720), forskolin were obtained from Tocris Bioscience; SR95531, NBQX, $N$-(piperidin-1-yl)-5-(4-iodophenyl)-1-(2,4-dichlorophenyl)-4methyl-1 H-pyrazole-3-carboxamide (AM-251) and NMDA were from Ascent; strychnine was from Sigma-Aldrich; $N$-[2-( $p$-bromocinnamyl-amino)ethyl]-5-isoquinolinesulfonamide dihydrochloride (H89) and 1,9-dideoxyforskolin were from BIOMOL; glycine was from Calbiochem; $N$-nitro-L-arginine (L-NNA) was from Cayman Chemical; and 8-(4-chlorophenylthio)adenosine- $3^{\prime}, 5^{\prime}$-cyclic monophosphorothioate, $\mathrm{Sp}$-isomer (Sp-8-CPT-cAMPS) was from BioLog Life Science Institute.

\section{Results}

A physiologically relevant stimulation of glutamatergic inputs induces a lasting increase in spontaneous GABA release

Sensory stimulation triggers a burst of action potentials in granule cells at $\sim 80 \mathrm{~Hz}$ (Chadderton et al., 2004). Because the axons of glutamatergic granule cells (PFs) innervate stellate cells in the molecular layer, we tested whether a brief burst of PF stimulation could effectively induce a long-lasting change in inhibitory transmission. Because cerebellar stellate cells receive inhibitory inputs from other stellate cells, we monitored spontaneous GABA release by recording mIPSCs in stellate cells that were voltage clamped at $-30 \mathrm{mV}$ (Fig. $1 \mathrm{~A}$ ). PF stimulation using 15 trains (at $1 \mathrm{~Hz}$ ) of four depolarizations (at $100 \mathrm{~Hz}$ ) reliably triggered a long-lasting increase in the mIPSC frequency (Fig. $1 A-C, E$ ) $(73 \pm 11 \% ; n=7 ; p<0.05)$ in the absence of any change in the mIPSC amplitude $(-8.9 \pm 3.3 \% ; n=7)$. This result indicates that a sustained enhancement in spontaneous GABA release from stellate cells (I-LTP) had occurred after PF stimulation. Reducing the $\mathrm{PF}$ stimulation to five bursts also triggered a potentiation in mIPSC frequency in four of five cells (Fig. $1 D, E)$, and the average mIPSC frequency increased by $55 \pm 22 \%(n=5 ; p<0.04)$. Thus, a physiologically relevant $\mathrm{PF}$ stimulation is sufficient to induce a lasting increase in GABA release from stellate cells. In subsequent experiments, we used the 15 train protocol to reliably induce I-LTP.

NMDA receptor activation enhances inhibitory transmission between two stellate cells via a presynaptic mechanism

Cerebellar stellate cells form inhibitory synapses onto each other (Palay and Chan-Palay, 1974; Llano and Gerschenfeld, 1993; Kondo and Marty, 1998) and transmission between synaptically connected stellate cells may influence the activity of inhibitory interneuron network. Our recent study showed that burst stimulation of PF inputs can increase GABA release at the autaptic stellate cell synapse (Liu and Lachamp, 2006). To test whether glutamate release from PFs also modulates inhibitory transmis- 

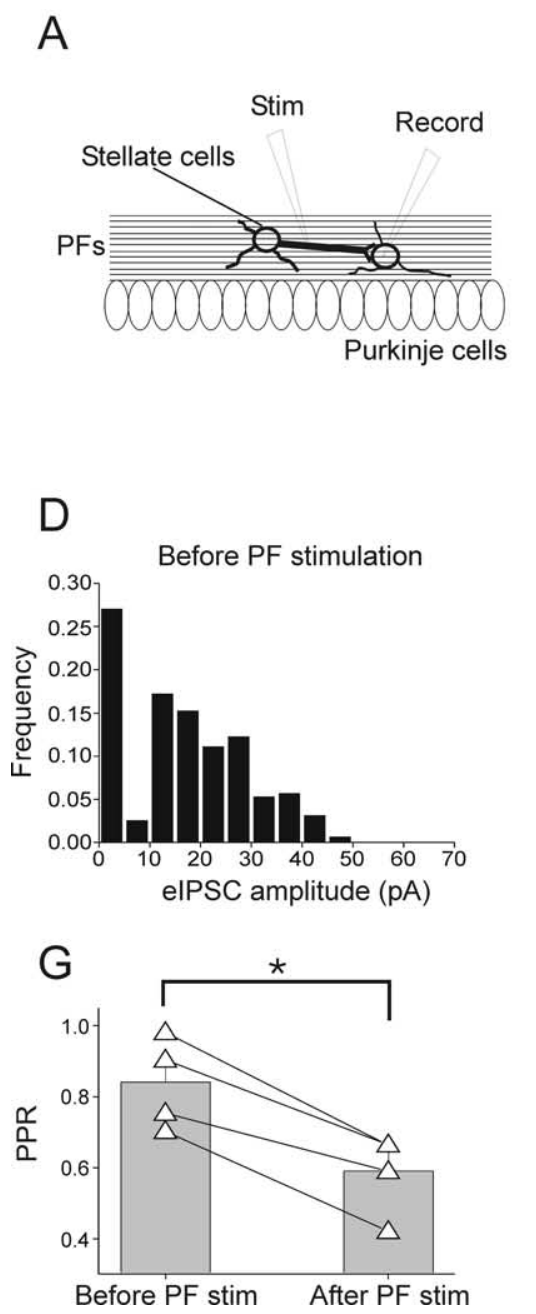
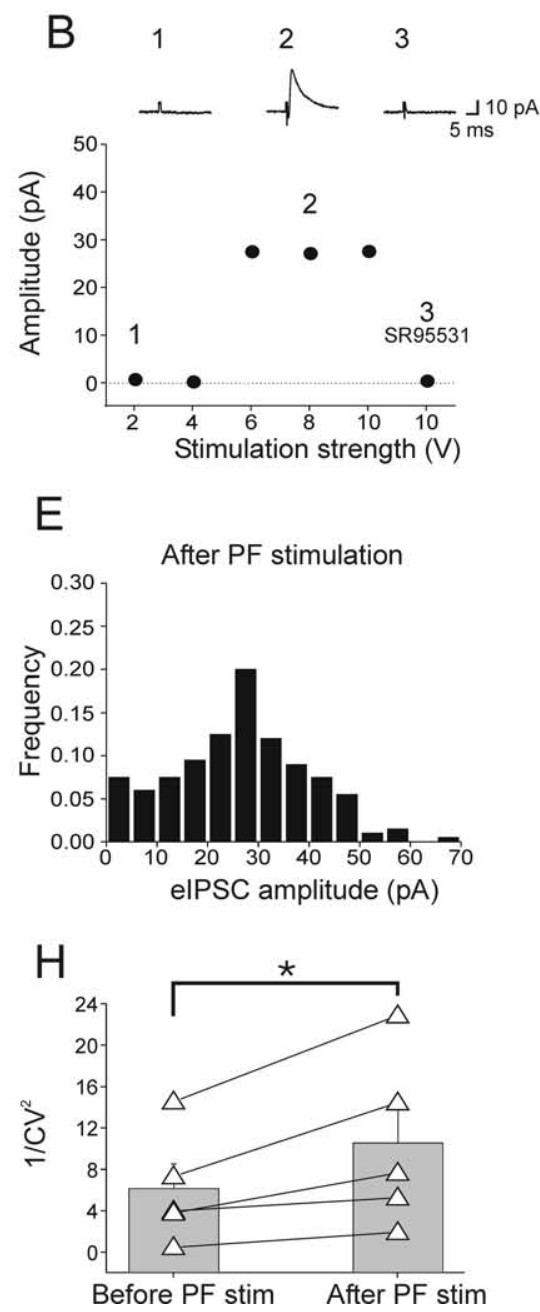
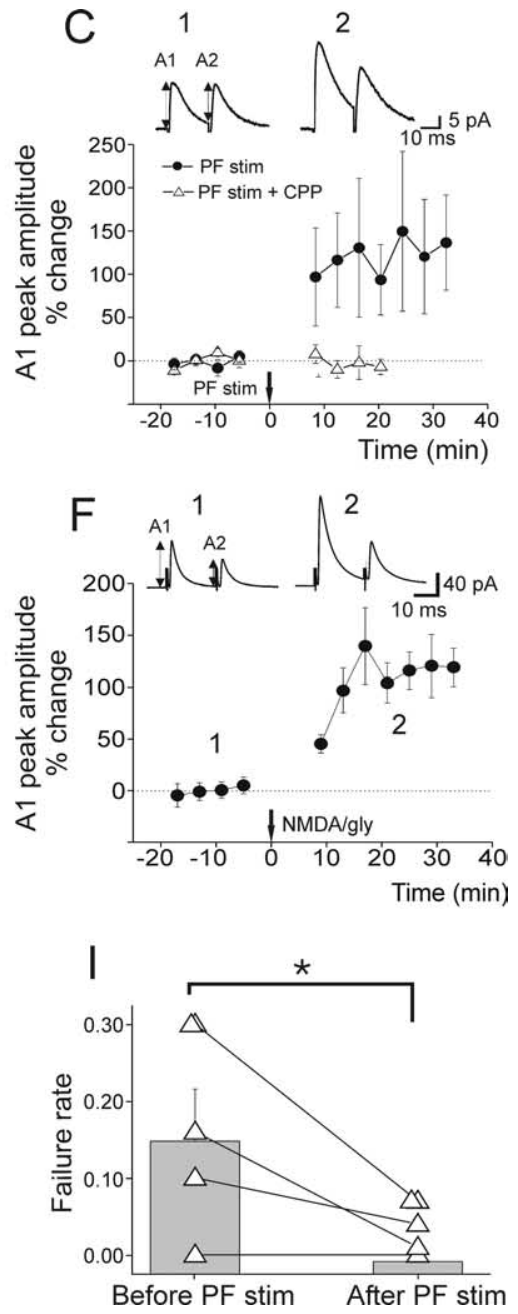

Figure 2. Evoked GABA release at the stellate-to-stellate cell synapse is enhanced by PF stimulation. $\boldsymbol{A}$, Schematic of the experimental protocol. $\boldsymbol{B}$, Evoked currents arose from the input of a single presynaptic GABAergic neuron. Example traces are the average of 20 consecutive sweeps. C, elPSCs recorded from a stellate cell before, and after PF stimulation with (triangles) or without (filled circles) $20 \mu \mathrm{M}$ CPP. Example traces were the average of 50 consecutive sweeps before (left) and after (right) I-LTP induction without CPP. D, E, elPSC amplitude distribution histograms from the cell illustrated in $\boldsymbol{C}$ before (D) and after (E) PF stimulation. $\boldsymbol{F}$, A brief (30 s) application of $30 \mu \mathrm{m} \mathrm{NMDA}$ and $20 \mu \mathrm{m}$ glycine triggered a lasting increase in elPSC amplitude. Time course of evoked IPSCs (group data; $n=5$ ). IPSCs were evoked by two PF depolarizations separated by $20 \mathrm{~ms}$ and were recorded in the presence of $5 \mathrm{~mm}$ kynurenic acid to block NMDARs and AMPARs. $A_{1}$ and $A_{2}$ represent the amplitudes of the first and the second evoked IPSCs, respectively. The example traces are average IPSCs from 50 events. G-I, PF stimulation altered the paired-pulse ratio, coefficient of variation, and failure rate of evoked IPSCS. G, The paired-pulse ratio was calculated as the ratio of $A_{2}$ to $A_{1}$. The PPR in one cell was not determined because of a large increase in the spontaneous IPSC frequency after the first elPSC. $\boldsymbol{H}$, Changes in the CV of the amplitude of the first IPSCS. I, Failure rate of the first IPSCs decreased after PF stimulation. $\mathbf{G}-\mathbf{I}$, Individual cells are shown as open triangles. The histogram bars represent the average value. Error bars indicate SEM. ${ }^{*} p<0.05$.

sion at the nonautaptic inhibitory synapse, we examined inhibitory synaptic transmission between two stellate cells.

We evoked inhibitory synaptic currents by placing a stimulating electrode $\sim 80 \mu \mathrm{m}$ from the recorded stellate cell (Fig. $2 A$ ). Increasing the stimulation strength did not further increase the amplitude of evoked IPSCs (Fig. 2 B), indicating that the postsynaptic cell received an input from a single presynaptic cell. The synaptic current was blocked by $20 \mu \mathrm{M}$ SR95531 (Fig. 2 B) and is thus mediated by $\mathrm{GABA}_{\mathrm{A}}$ receptors.

Evoked inhibitory synaptic currents were recorded in the presence of $5 \mathrm{~mm}$ kynurenic acid to block NMDA and AMPA receptors and $1 \mu \mathrm{M}$ strychnine to block glycine receptors (Fig. $2 C$, left traces). After 15 min of stable recording, kynurenic acid was washed out, and during this time we stimulated PFs. After stimulation (and after the reintroduction of kynurenic acid), the amplitude of the evoked IPSCs increased by $116 \pm$ $42 \%(n=5 ; p<0.05)$, an effect that lasted for at least $30 \mathrm{~min}$ (Fig. $2 C-E$ ). The potentiation was prevented by the presence of NMDA receptor blockers, CPP $(10 \mu \mathrm{M})$ and 7-chlorokynurenic acid $(20 \mu \mathrm{M})$, during the PF stimulation (Fig. $2 C$ ). Furthermore a brief application of $15-30 \mu \mathrm{M}$ NMDA and 20 $\mu \mathrm{M}$ glycine also induced a lasting increase in eIPSC amplitude $(117 \pm 10 \% ; n=5 ; p<0.05)$ (Fig. $2 F)$. Thus, NMDA receptor activation produced a sustained potentiation of evoked IPSC amplitude.

To determine whether the potentiation was attributable to an increase in GABA release from stellate cells, we measured the paired-pulse ratio, the coefficient of variation, and the failure rate of evoked IPSCs. Inhibitory synaptic currents were evoked by two consecutive presynaptic stimuli separated by a $20 \mathrm{~ms}$ interval. Activation of NMDA receptors reduced the paired-pulse ratio (Fig. $2 C, F, G)\left(\mathrm{PPR}=A_{2} / A_{1}\right.$; from $0.84 \pm$ 0.06 to $0.59 \pm 0.06 ; n=4 ; p<0.005$ ) and the failure rate (Fig. $2 D, E, I)$ (before stimulation, $0.17 \pm 0.06$; after stimulation, $0.04 \pm 0.01 ; n=5 ; p<0.05)$, indicating an increase in GABA release. Consistent with a presynaptic mechanism, $1 / \mathrm{CV}^{2}$ 


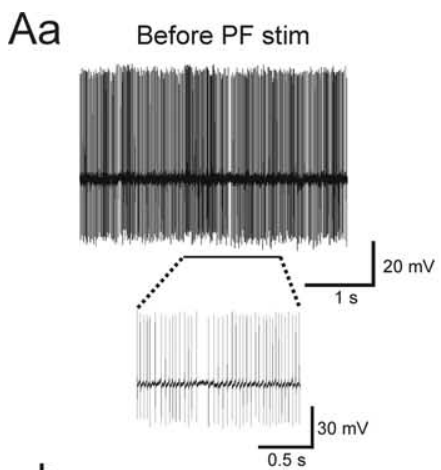

b

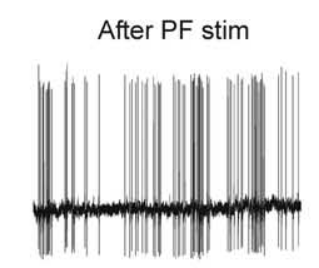

C After PF stim + SR95531

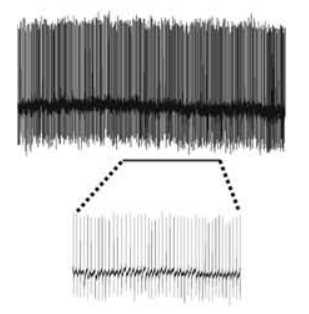

$\mathrm{Ba}$

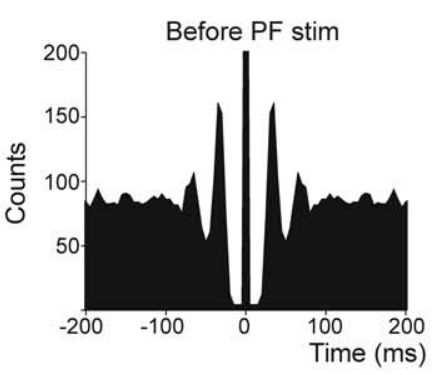

b
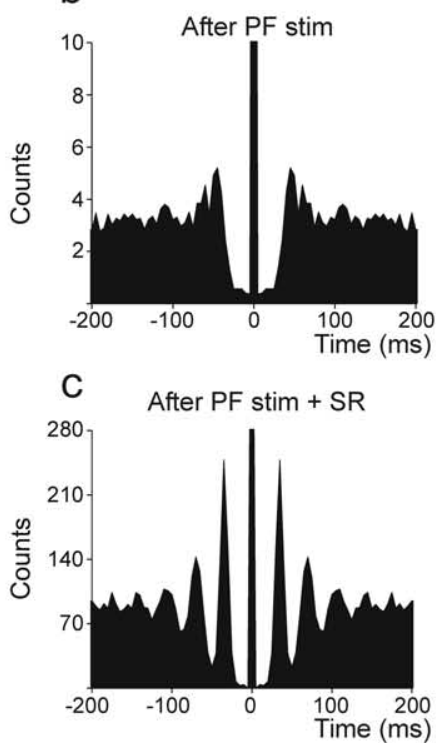

$\mathrm{Ca}$

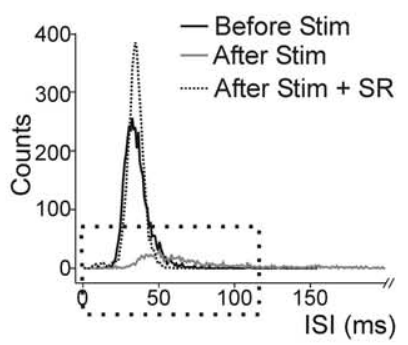

b

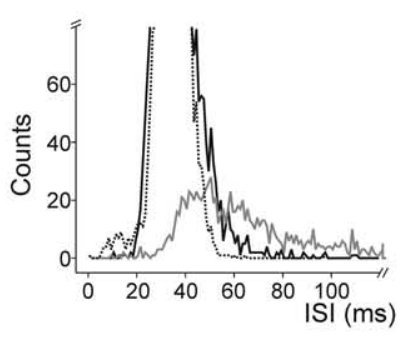

C

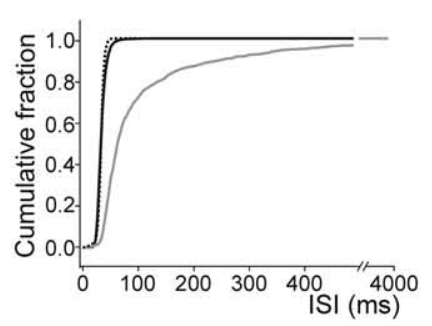

D
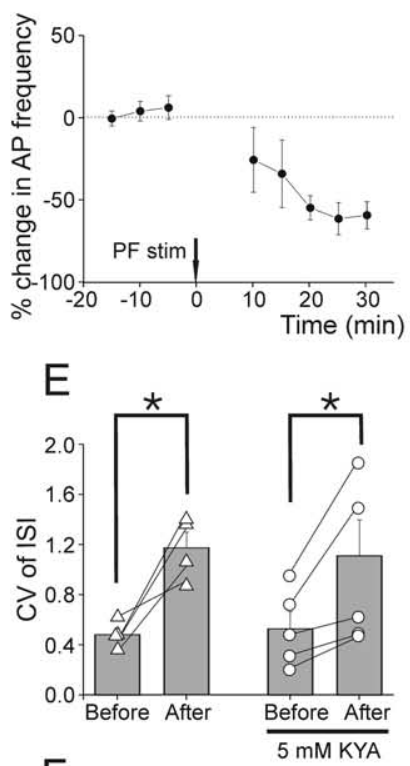

$\mathrm{F}$

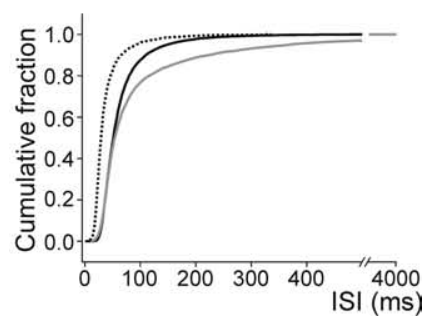

Figure 3. Parallel fiber stimulation alters interneuron action potential firing. $\boldsymbol{A}$, Example of action potentials recorded extracellularly from a stellate cell in control ( $\boldsymbol{A} \boldsymbol{a}), 15 \mathrm{~min}$ after $\mathrm{PF}$ stimulation $(\boldsymbol{A} \boldsymbol{b})$, and $30 \mathrm{~min}$ after stimulation in the presence of $20 \mu \mathrm{m}$ SR955321 (Ac). Note that APs became highly irregular after PF stimulation but were regular when inhibitory transmission was blocked. $B$, Autocorrelation of spontaneous APs from the corresponding recordings in $A$. Note that peaks in the autocorrelogram disappeared after PF stimulation and multiple peaks became evident in the presence of a GABA receptor blocker. C, Distribution of the ISI of APs. C $b$ is an enlargement from the boxed area in Ca. Ccillustrates the cumulative distribution of the ISI from the same data set. $D$, PF stimulation triggered a lasting decrease in the AP firing frequency. Firing frequencies were calculated during a 5 min window. $E$, The $C V$ of the ISl increased after PF stimulation as the firing pattern became more irregular. The open circles represent cells recorded in the presence of $5 \mathrm{~mm}$ kynurenic acid $(n=5)$, and the open triangles represent cells recorded without kynurenic acid ( $n=4)$. The bars represent the average $C V$ value before and after stimulation. Error bars indicate SEM. ${ }^{*} p<0.05$. $\boldsymbol{F}$, Example of the cumulative distribution of the ISI of APs recorded when 5 mm kynurenic acid was included (a different cell from the one shown in C). Shown are before (black line), after PF stimulation (gray line), and in the presence of a $\mathrm{GABA}_{\mathrm{A}} \mathrm{R}$ blocker (dotted line).

(Faber and Korn, 1991) also increased after PF stimulation (Fig. $2 H$ ) (from $6.0 \pm 2.4$ to $10.4 \pm 3.7 ; n=5 ; p<0.05$ ). Furthermore, CPP prevented the PF stimulation-induced changes in PPR and $1 / \mathrm{CV}^{2}$ (before stimulation: PPR, $0.57 \pm$ 0.12; $1 / \mathrm{CV}^{2}, 5.4 \pm 1.6$; after stimulation: PPR, $0.60 \pm 0.09$; $1 / \mathrm{CV}^{2}, 5.9 \pm 2.8 ; n=3$ ), suggesting that NMDAR activation induced a lasting increase in GABA release from stellate cells. $\mathrm{PF}$ stimulation also triggered a sustained increase in the frequency of miniature IPSCs in stellate cells (Fig. 1). These results indicate that the lasting enhancement in inhibitory transmission between two stellate cells is expressed presynaptically and arises as a consequence of an increase in the presynaptic release of GABA. To test whether asynchronous release at the stellate cell-to-stellate cell synapse was also altered, we measured the spontaneous IPSC frequency before and after the evoked IPSCs. PF stimulation did not alter the IPSC frequency or amplitude [control ratio of IPSC frequency, $0.93 \pm 0.13$; after PF stimulation, $0.82 \pm 0.16(n=4$; events measured 20-120 ms after the second evoked IPSC relative to that before the first evoked IPSC)].
Parallel fiber stimulation induces a lasting change in the interneuron firing pattern and frequency

Although stellate cells spontaneously fire action potentials in the absence of synaptic input, the firing pattern is usually controlled by a tonic inhibitory input (Häusser and Clark, 1997). We can therefore predict that an enhancement of GABA release from stellate cells would reduce the firing frequency and alter the firing pattern of synaptically connected stellate cells.

To determine the impact of the PF-mediated enhancement of GABA release, we recorded the activity of stellate cells at $35^{\circ} \mathrm{C}$ using an extracellular electrode. After obtaining a stable recording, PFs were stimulated using the I-LTP induction protocol. Action potentials were then subsequently recorded for at least 30 $\min$.

Before PF stimulation, stellate cells spontaneously fired action potentials at $8.5 \pm 2.7 \mathrm{~Hz}(n=6)$. The spiking activity was irregular (Fig. 3Aa), as shown by the variable interspike interval (ISI), which had a coefficient of variation of $0.54 \pm 0.07(n=6)$. This was also evident from the lack of multiple peaks in the autocorrelogram (Fig. $3 \mathrm{Ba}$ ). The irregular action potential firing pattern 

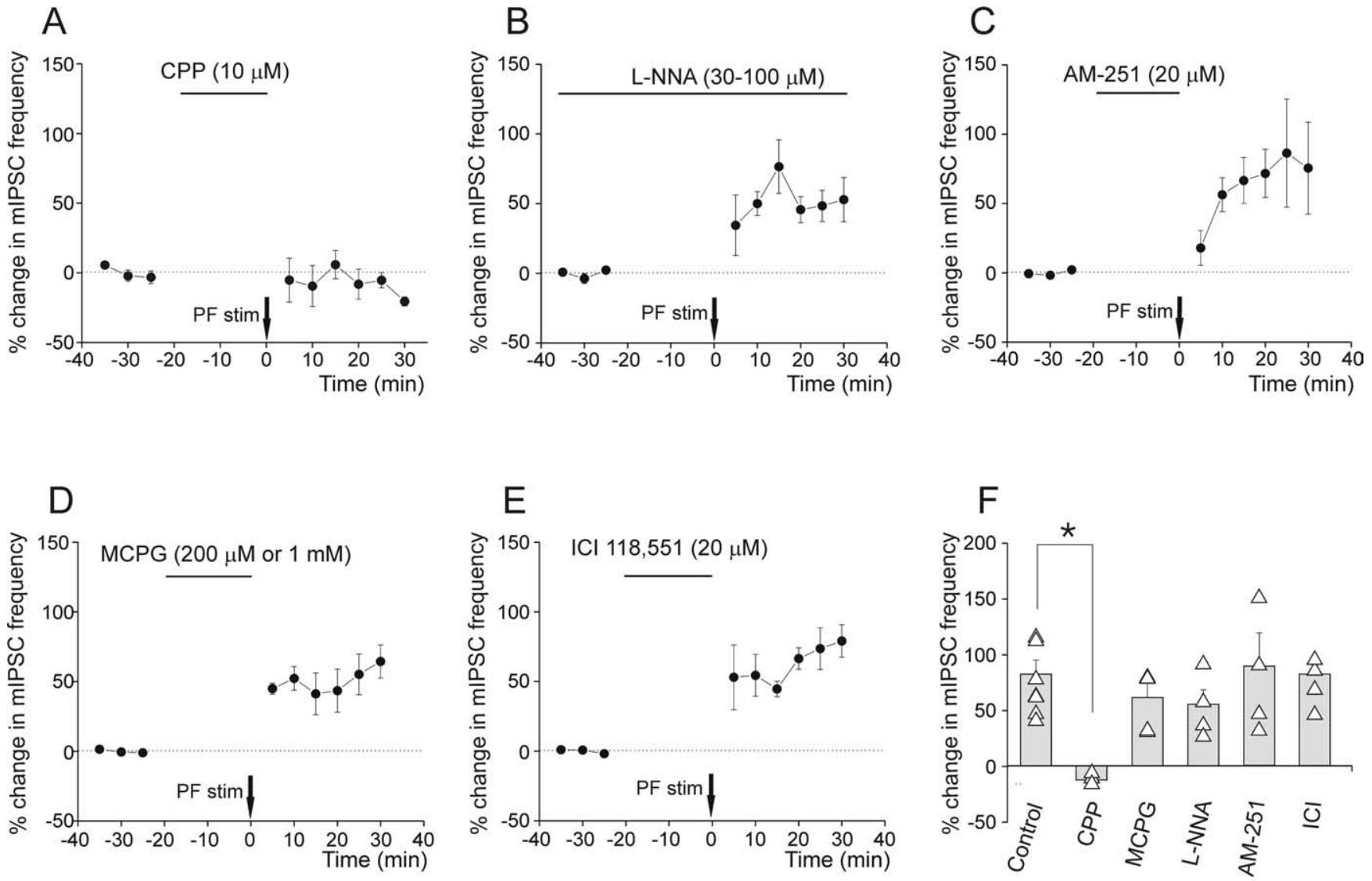

Figure 4. The induction of I-LTP requires activation of NMDA receptors, but not group I and II mGluRs, N0 synthase, CB1Rs, or $\beta$-adrenergic receptors. $\boldsymbol{A}$, Application of $10 \mu \mathrm{m}$ CPP, an NMDA

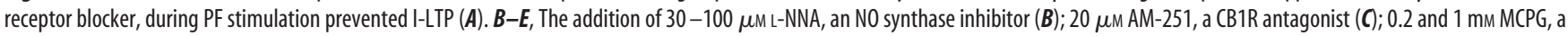
mGluR blocker (D); or $10 \mu \mathrm{m} \mathrm{ICI} \mathrm{118,551,} \mathrm{a} \beta$-adrenergic receptor blocker (E), did not block I-LTP. $\boldsymbol{F}$, Summary data. Error bars indicate SEM. ${ }^{*} p<0.05$.

arose from tonic inhibition because blockade of $\mathrm{GABA}_{\mathrm{A}}$ receptors by SR95531 increased the firing rate by $68.5 \pm 16.9 \%(n=6$; $p<0.02)$ and reduced the CV of the ISI from $0.54 \pm 0.07$ to $0.36 \pm 0.08(n=6 ; p<0.002)$, consistent with previous observations (Häusser and Clark, 1997). In the presence of SR95531, the autocorrelogram exhibited multiple peaks indicating a highly regular firing pattern (Fig. $3 A c, B c$ ).

After PF stimulation, the spontaneous action potential firing frequency decreased by $60 \pm 7 \%$, from $26.3 \pm 8.3$ to $10.9 \pm 5.1$ $\mathrm{Hz}(n=4 ; p<0.05)$. This suppression lasted for at least $30-40$ min (Fig. $3 D$ ). At the same time, the action potential firing became highly irregular (Fig. $3 A b, B b$ ) as indicated by the increase in the CV (Fig. $3 E$ ) from $0.48 \pm 0.05$ to $1.17 \pm 0.13(n=4 ; p<0.05)$ and the appearance of a single small peak in the autocorrelogram (Fig. $3 B b$ ). To confirm that these changes were indeed associated with increased inhibitory transmission, SR95531 was applied to block $\mathrm{GABA}_{\mathrm{A}}$ receptors at the end of the recording (Fig. $3 A c, B c$ ). SR95531 completely reversed the PF stimulation-induced change in action potential firing. The firing frequency increased to the control level or above (Fig. $3 A c, C a-C c$ ). The firing pattern now showed a striking regularity (Fig. $3 A c$ ) and large, multiple peaks in the autocorrelogram (Fig. $3 \mathrm{Bc}$ ). These results strongly suggest that an increase in inhibitory transmission gives rise to a change in the frequency and pattern of action potential firing in stellate cells.

Theoretically, an enhanced inhibitory transmission could result from a direct increase in GABA release, or indirectly from a potentiation of excitatory transmission at the PF-to-stellate cell synapse (Rancillac and Crépel, 2004). To determine the contribution of enhanced GABA release, we blocked excitatory synaptic currents during action potential recordings with $5 \mathrm{~mm}$ kynurenic acid to eliminate disynaptic inhibition. Kynurenic acid was washed out during PF stimulation and reintroduced after stimulation. PF stimulation reduced the action potential firing rate (before stimulation, $8.3 \pm 1.4 \mathrm{~Hz}$; after stimulation, $5 \pm 1 \mathrm{~Hz}$; $n=5 ; p<0.02)$ and prolonged the ISI. This was seen as a rightward shift in the cumulative probability distribution of the ISI (Fig. $3 F$ ). After stimulation, AP firing became markedly irregular, as indicated by an increase in the CV of the ISI (Fig. $3 E$ ) (before stimulation, $0.53 \pm 0.3$; after stimulation, $1.1 \pm 0.3 ; n=5 ; p<$ $0.05)$. This result indicates that an enhancement of GABA release from stellate cells significantly contributed to the change in action potential firing rate and pattern. Thus I-LTP can regulate interneuron spiking activity.

\section{Induction of I-LTP requires NMDARs, but is independent of NO, CBR1, and $\boldsymbol{\beta}$-adrenergic receptor activation}

We next investigated the molecular events that link the release of glutamate from PFs to an increase in GABA release from stellate cells. NMDA receptor blockers, CPP $(10 \mu \mathrm{M})$ and 7-chlorokynurenic acid $(20 \mu \mathrm{M})$, both blocked the PF stimulationinduced lasting increase in mIPSC frequency (Fig. 4A) $(-11 \pm$ $3 \% ; n=3)$ and prevented the potentiation of evoked IPSC amplitude (Fig. 2C). Thus activation of NMDARs is required for the induction of I-LTP.

Our previous study showed that $\mathrm{Ca}^{2+}$ influx is necessary to 

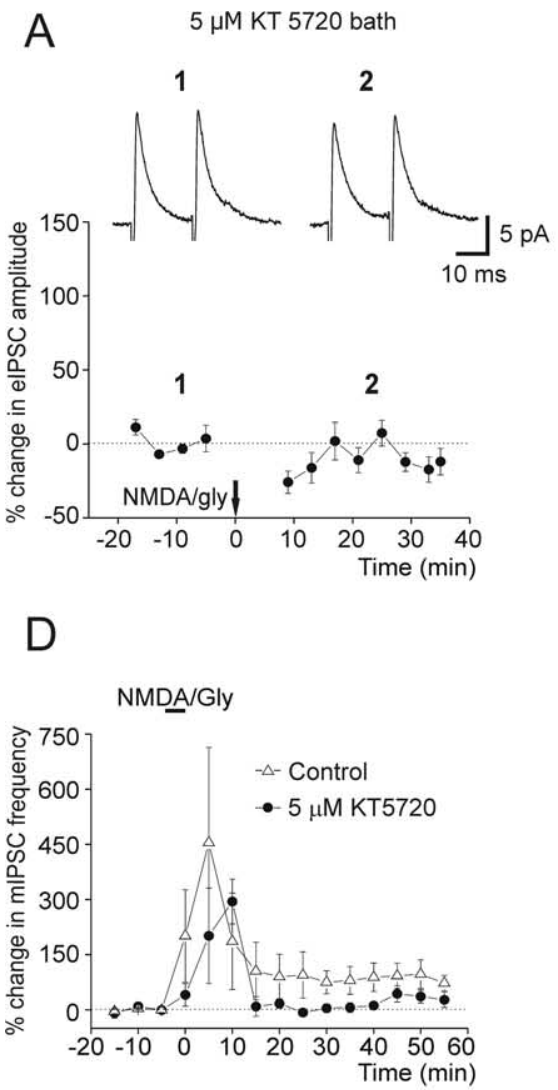

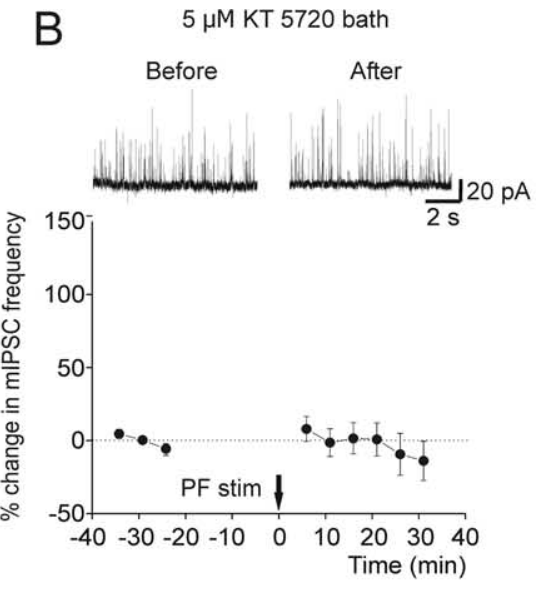

$E$

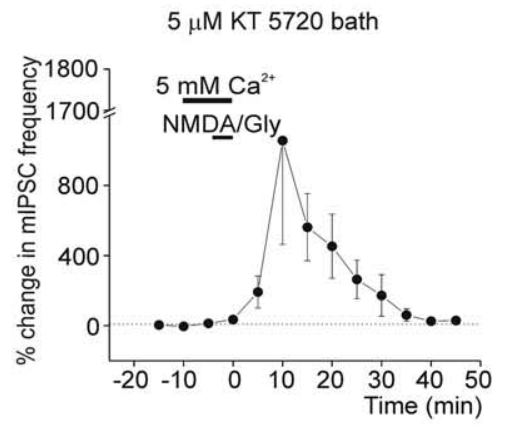

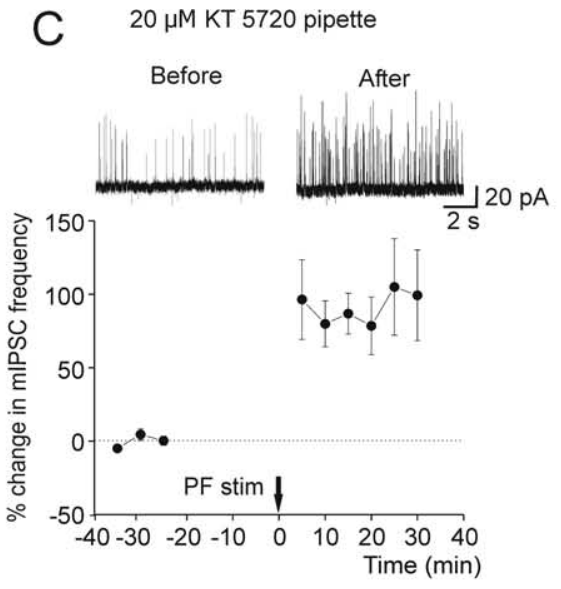

$\mathrm{F}$

PF stimulation NMDA/glycine

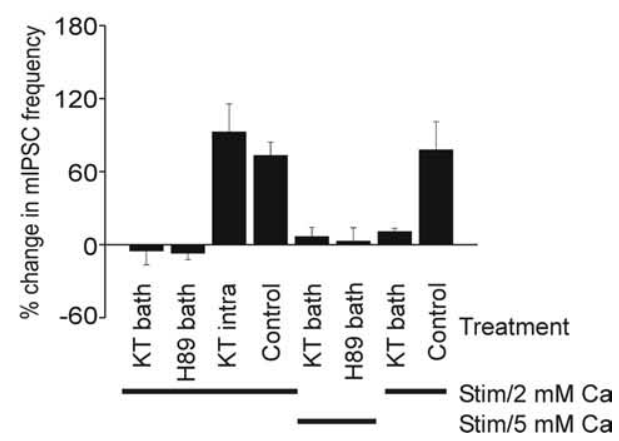

Figure 5. Inhibition of PKA by KT5720 blocks I-LTP. A, B, Cerebellar slices were incubated with $5 \mu \mathrm{m}$ KT5720, a PKA inhibitor, for $2 \mathrm{~h}$. Under these conditions, parallel fiber stimulation failed to induce a lasting increase in the amplitude of eIPSCS $(\boldsymbol{A})(n=3)$ and in the frequency of mIPSCS $(\boldsymbol{B})(n=5)$. $\boldsymbol{C}$, Inclusion of $20 \mu \mathrm{m}$ KT5720 in the pipette solution to selectively block PKA in the postsynaptic neuron did not inhibit I-LTP $(n=5)$. $\boldsymbol{D}$, Inhibition of PKA prevented the I-LTP induced by NMDA and glycine application ( $n=3 ;$ filled circles). The open triangles (control) are data from previous experiments reported by Liu and Lachamp (2006). $E$, The extracellular $\mathrm{Ca}^{2+}$ concentration was increased to 5 mM during NMDA and glycine application. Under these conditions, KT5720 prevented NMDAR-induced I-LTP $(n=6)$. F, Summary data (PF stimulation: H89 bath, $n=5$; control, $n=7$; NMDA/glycine application: H89, $n=5$ ). Error bars indicate SEM.

induce the lasting increase in mIPSC frequency (Liu and Lachamp, 2006). Inclusion of 10-20 mM BAPTA in the patch electrode has been shown to inhibit the AMPAR subtype switch in stellate cells that is induced by activation of NMDA and AMPA receptors (Liu and Cull-Candy, 2000; Sun and Liu, 2007). However intracellular application BAPTA failed to prevent I-LTP in stellate cells (Liu and Lachamp, 2006). Thus, a $\mathrm{Ca}^{2+}$ rise in the postsynaptic stellate cell is not required. This suggests that glutamate spillover activates NMDARs on the presynaptic neurons, most likely the presynaptic terminals of stellate cells (Duguid and Smart, 2004; Fiszman et al., 2005). However, activation of NMDARs/metabotropic glutamate receptors (mGluRs) or postsynaptic membrane depolarization can trigger the release of retrograde signals such as $\mathrm{NO}$ and endocanabinoids from stellate cells (Shin and Linden, 2005; Beierlein and Regehr, 2006) and Purkinje cells (Yoshida et al., 2002; Brown et al., 2003; Qiu and Knöpfel, 2007). We therefore tested for the possible involvement of these messengers in the induction of I-LTP.

As shown in Figure 4, $B$ and $F$, in the presence of 30-100 $\mu \mathrm{M}$ L-NNA, a potent inhibitor of NO synthase, PF stimulation still induced an increase in mIPSC frequency $(49 \pm 11 \% ; n=5 ; p<$ $0.03)$. Inclusion of AM-251 (20 $\mu \mathrm{M})$, a CB1R antagonist, during the PF stimulation also failed to prevent the I-LTP induction (Fig. $4 C)$ because the mIPSC frequency increased by $79 \pm 26 \%(n=4$; $p<0.05)$. Finally, MCPG $(200 \mu \mathrm{M}$ and $1 \mathrm{~mm})$, a group I and II mGluR blocker, did not prevent the PF-induced increase in
mIPSC frequency (Fig. $4 D)(54.4 \pm 13.7 \% ; n=4 ; p<0.03)$. This suggests that induction of I-LTP does not require the involvement of NO or endocanabinoids and that group I and II mGluRs are unlikely to be involved. Because the activation of $\beta$-adrenergic receptors on interneurons can lead to an increase in GABA release onto Purkinje cells (Saitow et al., 2005), we tested for the possible involvement of $\beta$-adrenergic receptors in the I-LTP. ICI 118,551, a specific blocker of $\beta$-adrenergic receptors, did not prevent the PF stimulation-induced increase in mIPSC frequency (Fig. $4 E)(73 \pm 10.7 \% ; n=4 ; p<0.05)$. Thus, $\mathrm{PF}$ stimulation-induced I-LTP is not mediated by $\beta$-adrenergic receptors.

Therefore, the induction of an increase in the GABA release from stellate cells requires activation of NMDA receptors, but does not depend on $\beta$-adrenergic receptor activation, endocanabinoids, or NO.

\section{I-LTP requires an increase in the cAMP level and the activation of PKA}

To determine the downstream signaling pathways after NMDA receptor activation, we first tested whether PKA activity regulated GABA release from cerebellar stellate cells. Application of $10 \mu \mathrm{M}$ $\mathrm{H} 89$, a PKA inhibitor, reduced the frequency of mIPSCs in stellate cells, whereas the mIPSC amplitude remained unchanged (supplemental Fig. $1 A$, available at www.jneurosci.org as supple- 
mental material). This indicates that PKA activity regulates GABA release under basal conditions.

To determine whether PKA activation is required for I-LTP, we used two PKA inhibitors, KT5720 and H89. Cerebellar slices were preincubated with $5 \mu \mathrm{M}$ KT5720 for $2 \mathrm{~h}$, and $1 \mu \mathrm{M}$ KT5720 was present during the recording. Under these conditions, NMDA and glycine application failed to trigger a sustained increase in the amplitude of evoked IPSCs (Fig. 5A). PF stimulation also no longer induced a lasting enhancement in the frequency of mIPSCs (Fig. $5 B, F)(n=5$; frequency, $-4.9 \pm 11.6 \%$; amplitude, $-2.8 \pm$ $13.4 \%)$. Thus, inhibition of PKA prevented the PF stimulation-induced I-LTP. This was confirmed using another PKA inhibitor, H89 $(10 \mu \mathrm{M})$, which also blocked the I-LTP $(n=5$; frequency, $-6.8 \pm 5.5 \%$; amplitude, $-6.2 \pm 8 \%$ ) (Fig. 5F; supplemental Fig. $1 B$, available at www. jneurosci.org as supplemental material). These results indicate that lasting enhancement of both spontaneous and evoked GABA release from stellate cells requires PKA activation. When the recording pipette was loaded with KT5720 (20 $\mu \mathrm{M})$ to selectively inhibit postsynaptic PKA, PF stimulation still enhanced the mIPSC frequency by $92.4 \pm 23.3 \%$ (Fig. $5 C, F)(n=5 ; p<0.04)$. Thus, I-LTP requires PKA activation, but does not involve PKA activity in the postsynaptic neuron.

How does PKA activity regulate I-LTP? Because I-LTP induction requires both glutamate spillover and NMDA receptor activation (Liu and Lachamp, 2006), we examined the possibility that the PKA inhibition suppressed glutamate release from PFs, so reducing the activation of NMDARs. First, we tested the effect of H89 $(10 \mu \mathrm{M})$ on PF-evoked NMDAR-mediated currents. Slices were preincubated with H89 for $2 \mathrm{~h}$ before recording. A burst of PF stimulation evoked an NMDAR-mediated current in both control and H89-treated slices (supplemental Fig. 2, available at www.jneurosci.org as supplemental material) (NMDARmediated current charge in control, $55.9 \pm 13.7 \mathrm{nA} \cdot \mathrm{s}$; in H89treated cells, $38.5 \pm 6.7 \mathrm{nA} \cdot \mathrm{s} ; n=5 ; p>0.05)$. Thus, PKA inhibition did not significantly alter the current evoked by activation of extrasynaptic NMDARs. Second, if PKA inhibition blocked I-LTP by reducing glutamate release, direct activation of NMDARs by bath application of NMDA and glycine would be expected to induce I-LTP in the presence of a PKA inhibitor. After a $2 \mathrm{~h}$ incubation with $5 \mu \mathrm{M}$ KT5720, coapplication of NMDA and glycine did not trigger a long-lasting increase in the mIPSC frequency $(6.6 \pm 7.6 \% ; n=3)$. Instead, a transient increase in mIPSC frequency was observed in several cells during and immediately after the application of NMDA and glycine (Fig.
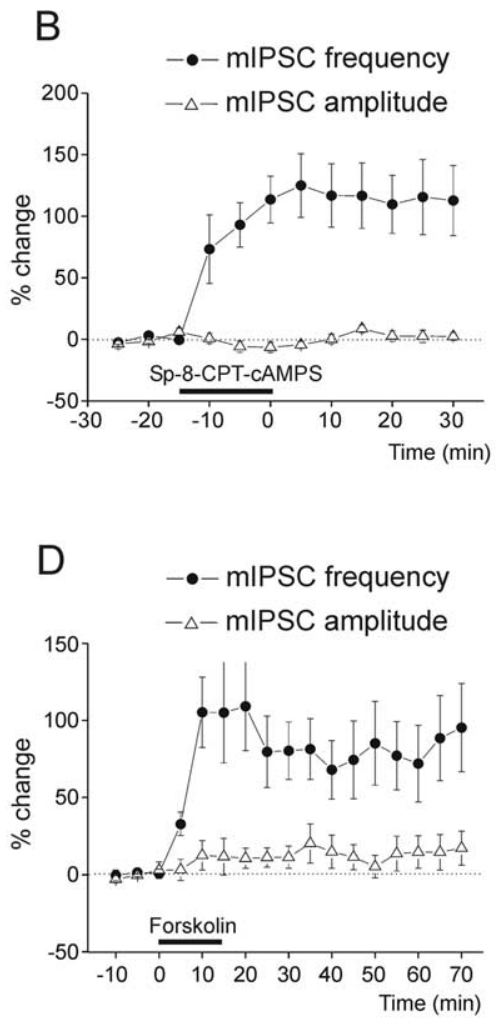

F

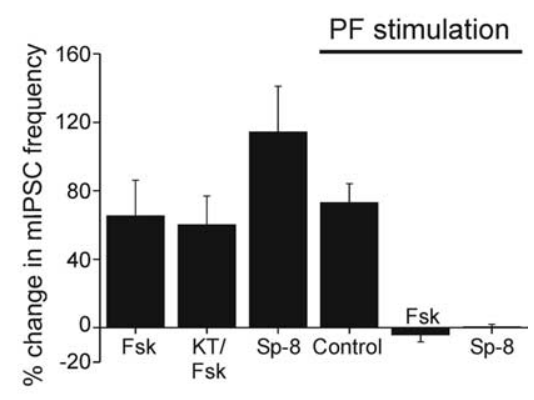

Figure 6. Increasing CAMP levels prevents I-LTP. A, Cerebellar slices were incubated with $100 \mu \mathrm{m}$ Sp-8-CPT-CAMPS for $2 \mathrm{~h}$ to increase the CAMP level. After this treatment, PF stimulation failed to induce a change in mIPSC frequency $(n=4) . B$, Application of $100 \mu \mathrm{M}$ Sp-8-CPT-CAMPS for 15 min induced a long-lasting increase in the mIPSC frequency without a change in the amplitude Application of $50 \mu \mathrm{m}$ forskolin for $15 \mathrm{~min}$ induced a long-lasting increase of the mIPSC frequency $(n=7)$. $\boldsymbol{E}$, PKA inhibition blocked the NMDAR-induced I-LTP, but did not prevent the forskolin-triggered lasting increase in mIPSC frequency $(n=3)$. $\boldsymbol{F}$, Summary data. Error bars indicate SEM.
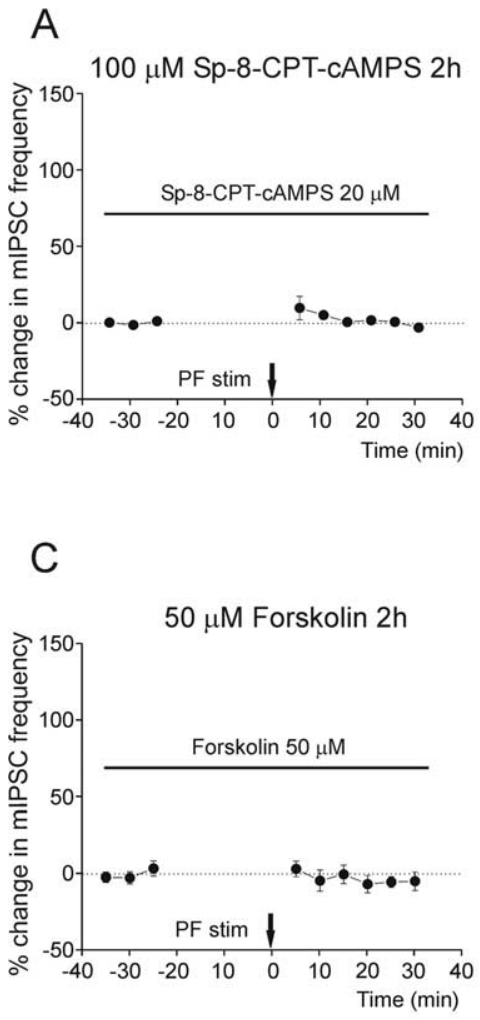

$E$

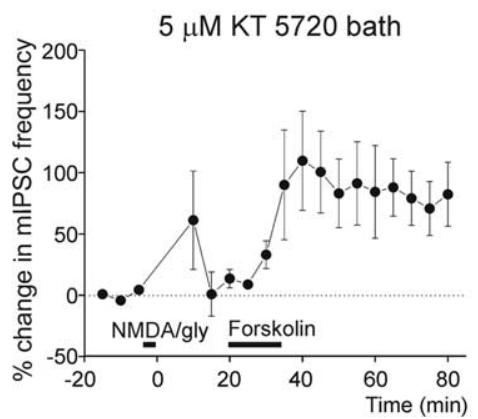

5D) as described in previous studies (Glitsch and Marty, 1999; Duguid and Smart, 2004; Liu and Lachamp, 2006). Thus, a reduction in glutamate release from PFs is unlikely to contribute to the blockade of I-LTP by PKA inhibitors.

PKA inhibition has been shown to reduce the $\mathrm{Ca}^{2+}$ permeability of NMDARs (Skeberdis et al., 2006). Because $\mathrm{Ca}^{2+}$ influx via these receptors is necessary to induce I-LTP (Liu and Lachamp, 2006), we increased the extracellular $\mathrm{Ca}^{2+}$ concentration to $5 \mathrm{~mm}$ to enhance $\mathrm{Ca}^{2+}$ influx and compensate for a possible inhibition of the NMDAR $\mathrm{Ca}^{2+}$ permeability by PKA inhibitors. In stellate cells pretreated with KT5720 or H89, NMDA/ glycine application in a high $\mathrm{Ca}^{2+}$ ACSF transiently enhanced mIPSC frequency, but failed to induce a lasting increase in GABA 
release (Fig. 5E,F) (KT5720, $10.6 \pm 1.3 \% ; n=6)$ (supplemental Fig. $1 C$, available at www.jneurosci.org as supplemental material) $(\mathrm{H} 89,2.4 \pm 11.1 \% ; n=5)$. Control cells from slices incubated in $0.02 \%$ DMSO (the solvent for PKA blockers) exhibited a normal I-LTP $(125.4 \pm 80.3 \% ; n=3 ; p<0.05)$. These results suggest that a reduction in $\mathrm{Ca}^{2+}$ entry through NMDARs was not responsible for preventing the I-LTP.

To confirm that an increase in the cAMP level in the presynaptic terminals is required, we used a cAMP analog, Sp-8-CPTcAMPS, and forskolin, an activator of adenylyl cyclase, to raise the cAMP level and enhance PKA activity, because we predicted that this should occlude any additional increase in GABA release triggered by PF stimulation. After treatment with $100 \mu \mathrm{M} \mathrm{Sp}-8$ CPT-cAMPS, parallel fiber stimulation failed to induce I-LTP in the presence of Sp-8-CPT-cAMPS (Fig. $6 A, F$ ). Incubation with $50 \mu \mathrm{M}$ forskolin also prevented I-LTP (Fig. 6C,F). Thus, an increase in cAMP production is required to trigger I-LTP.

Finally, we tested whether an increase in the cAMP level was sufficient to enhance spontaneous GABA release. Indeed, a short application (15 min) of $100 \mu \mathrm{M} \mathrm{Sp-8-CPT-cAMPS} \mathrm{triggered} \mathrm{a}$ long-lasting increase in mIPSC frequency (Fig. 6B) (114.2 \pm $26.8 \% ; n=5 ; p<0.03$ ) without any change in mIPSC amplitude $(1.8 \pm 3 \%)$. A lasting enhancement of mIPSC frequency was also observed after $50 \mu \mathrm{M}$ forskolin application (Fig. 6D) (frequency, $84.3 \pm 25.9 \% ; n=7 ; p<0.03$; amplitude, $17.3 \pm 11.1 \%)$.

However, the forskolin-induced increase in GABA release was independent of PKA activation. After KT5720 treatment, NMDA and glycine application failed to induce I-LTP, but a brief application of $50 \mu \mathrm{M}$ forskolin still triggered a sustained increase in mIPSC frequency (Fig. 6E). As a control, 1,9-dideoxyforskolin, an inactive forskolin analog, did not produce an enduring increase in GABA release (data not shown) $(6.9 \pm 7.7 \%$; $n=3)$. Thus, the forskolin-induced increase in MIPSC frequency requires elevated cAMP levels, but does not entirely depend on PKA activation, consistent with previous observations (Lonart et al., 1998; Beaumont and Zucker, 2000; Castillo et al., 2002; Zhong and Zucker, 2005).

Together, these results show that PF stimulation-induced I-LTP requires an increase in CAMP production and PKA activation. Our results are consistent with a presynaptic site of PKA activation, but we cannot rule out that other neurons or glial cells are possible sites of PKA activation.

\section{RIM1 $\alpha$, an active zone protein, is required for I-LTP}

RIM $1 \alpha$ is a protein that is localized to the active zone and participates in the regulation of neurotransmitter release at both glutamatergic and GABAergic terminals (Schoch et al., 2002). RIM1 $\alpha$ is a substrate for PKA, and phosphorylation of RIM $1 \alpha$ by PKA is required for presynaptic LTP at a number of excitatory synapses (Castillo et al., 2002; Lonart, 2002; Lonart et al., 2003).

Using RIM $1 \alpha^{-l-}$ mice, we examined the role of RIM $1 \alpha$ in I-LTP. We first tested whether deletion of RIM $1 \alpha$ altered the basal excitability of stellate cells. We recorded spontaneous action potentials in stellate cells and observed no difference in the amplitude, the afterhyperpolarization (AHP), and half-width of spontaneous action potentials between RIM $1 \alpha^{-/-}$and wild-type stellate cells (Table 1). Depolarizing current injections evoked action potentials at the same frequency in both RIM1 $\alpha^{-/-}$and wild-type stellate cells (Fig. $7 A, B$ ). Hence the baseline excitability of stellate cells is unchanged in $\operatorname{RIM} 1 \alpha^{-1-}$ mice.

Because the activation of NMDARs by glutamate released from PFs is required for the induction of I-LTP, we tested whether the probability of glutamate release was altered at the
Table 1. Neuronal excitability characterized in wild-type and $\mathrm{RIM1}^{-/-}$mice: action potential properties

\begin{tabular}{llll}
\hline & Peak amplitude $(\mathrm{mV})$ & AHP $(\mathrm{mV})$ & Half-width $(\mathrm{ms})$ \\
\hline Wild type $(n=7)$ & $56.2 \pm 2.8$ & $-26.78 \pm 3.7$ & $0.9 \pm 0.04$ \\
RIM1 $\alpha^{-I-}(n=8)$ & $52.6 \pm 1.4$ & $-31.9 \pm 3.2$ & $0.8 \pm 0.1$ \\
$t$ test & $p=0.2$ & $p=0.3$ & $p=0.1$ \\
\hline
\end{tabular}

The amplitude of action potentials and AHP were measured from the resting membrane potential. Basal inhibitory and excitatory transmission, and spontaneous action potential properties were not significantly different between wild-type and Rim $1^{-1-}$ mice.

PF-to-stellate cell synapse in RIM1 $\alpha$ knock-out mice. Glutamate release was evaluated using the paired-pulse ratio of EPSCs evoked by stimulation of PFs in stellate cells. We detected no difference in the paired-pulse ratio of EPSCs between RIM $1 \alpha^{-1-}$ and wild-type animals (Table 2), consistent with observations at the PF-to-Purkinje cell synapse (Castillo et al., 2002). To determine the ability of burst PF stimulation to activate NMDARmediated currents in stellate cells, we measured extrasynaptic NMDAR-mediated currents evoked by PF stimulation when stellate cells were voltage clamped at $+40 \mathrm{mV}$. The stimulationevoked NMDAR-mediated currents in RIM1 $\alpha^{-1-}$ animals had similar amplitude and kinetics to the wild-type mice (Fig. 7C) (NMDAR-mediated current charge: wild type, $55.9 \pm 13.7 \mathrm{nA} \cdot \mathrm{s}$; RIM $1 \alpha^{-/-}, 45.3 \pm 28.6 \mathrm{nA} \cdot \mathrm{s} ; n=5$; not significant). These data suggest that glutamate release and spillover from PFs is not altered in the RIM $1 \alpha^{-1-}$ mouse.

The basal release of GABA from stellate cells was also not altered in the RIM $1 \alpha^{-/-}$mice because the frequency and amplitude of mIPSCs in stellate cells and the paired-pulse ratio of evoked IPSCs was not different between wild-type and knock-out animals (Table 2).

We then investigated whether I-LTP could still be induced in RIM $1 \alpha^{-1-}$ cerebellar slices. Burst stimulation of parallel fibers failed to induce a change in the frequency and amplitude of mIPSCs (Fig. 7D,E) (frequency, $-4.8 \pm 5.1 \%$; amplitude, $-22.5 \pm$ $10.5 \% ; n=5$ ). Consistent with the involvement of RIM1 $\alpha$ in I-LTP, bath application of NMDA and glycine also did not trigger a lasting increase in mIPSC frequency (Fig. 7F). Because PF stimulation and NMDA/glycine application can both induce I-LTP in wild-type mice (Figs. 1C, 5D), these results shows that the active zone protein RIM1 $\alpha$ is essential for I-LTP.

\section{Discussion}

Recent studies have revealed that sensory and emotional experiences can give rise to long-lasting changes in inhibitory synaptic transmission in a number of brain regions, including the cerebellum (Lien et al., 2006; Maffei et al., 2006; Nugent et al., 2007; Scelfo et al., 2008). In this study, we showed that a physiologically relevant stimulation can induce a lasting increase in GABA release from cerebellar stellate cells. Our results indicate that the molecular mechanism(s) underlying I-LTP involve the elevation of cAMP levels, the activation of PKA, and require RIM1 $\alpha$. This sustained increase in GABA release alters the firing pattern of stellate cells and thus will modify interneuronal network activity within the cerebellum.

Sensory stimulation has been shown to evoke a short burst of action potentials at high frequency in cerebellar granule cells in vivo (Chadderton et al., 2004). This type of activity results in glutamate spillover and the activation of extrasynaptic NMDA receptors in cerebellar interneurons (Carter and Regehr, 2000; Clark and Cull-Candy, 2002; Sun and Liu, 2007). Here, we show that just a few bursts of PF activity that mimic the in vivo firing pattern of granule cells are sufficient to induce I-LTP, which is 
A
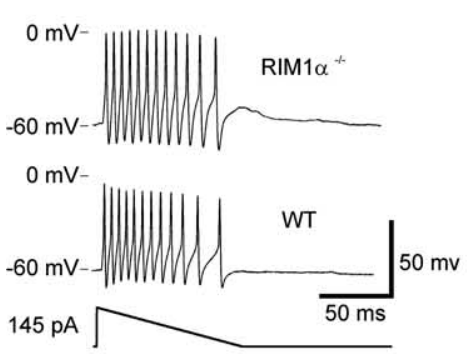

D

mIPSCs before PFstimulation

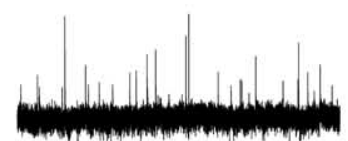

mIPSCs after PF stimulation

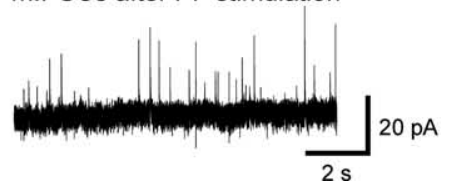

B
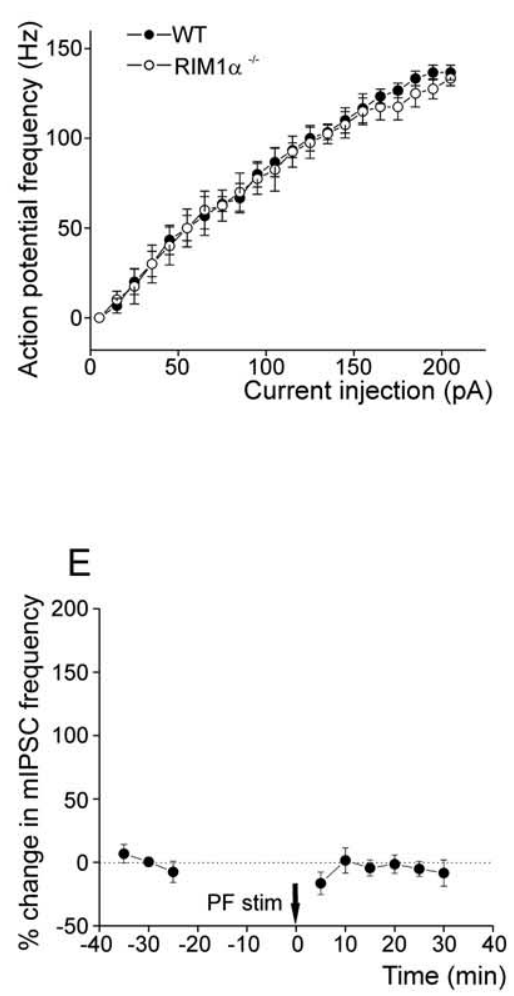

C NMDA current - Wild Type
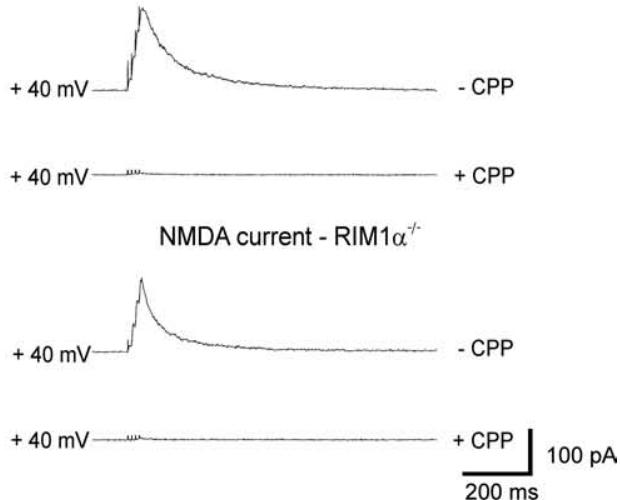

$\mathrm{F}$

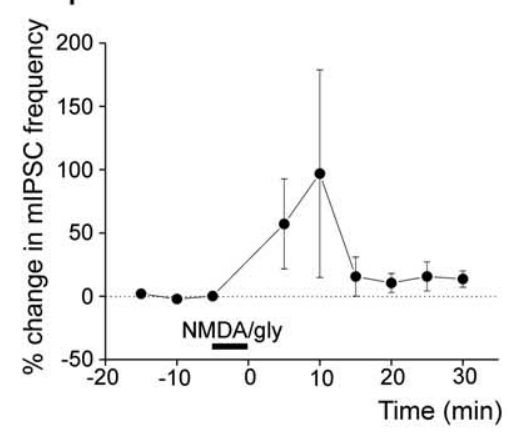

Figure 7. I-LTP requires RIM1 $\alpha . A$, A ramp of depolarizing current (bottom trace) mimicking an NMDAR-mediated synaptic current was used to trigger action potential firing in stellate cells from wild-type (WT) (middle trace) and RIM1 $\alpha^{-1-}$ mice (top trace). $\boldsymbol{B}$, The frequency of the evoked action potentials during the ramp was plotted against the peak amplitude of the current injection (WT, $n=7$; mutant, $n=8$ ). C, A burst of PF stimulation evoked an NMDAR-mediated current in stellate cells from a wild-type mouse and a RIM1 $\alpha^{-1-}$ mouse. D, E, Parallel fiber stimulation failed to trigger an increase in the mIPSC frequency in RIM1 $\alpha^{-/-}$mice $(n=5) . F$, NMDA and glycine application also did not induce an increase in the mIPSC frequency in RIM1 $\alpha^{-1-}$ mice with the exception of one cell that showed a $41 \%$ potentiation $(n=6)$. Error bars indicate SEM.

manifested as a long-lasting increase in GABA release from stellate cells. This effect requires the activation of NMDA receptors in presynaptic stellate cells (Liu and Lachamp, 2006). These results raise the possibility that the NMDAR-mediated sustained enhancement of GABA release could occur in vivo and may participate in associative memory formation in the cerebellum (Scelfo et al., 2008).

Glutamate can regulate inhibitory transmitter release via postsynaptic NMDA or metabotropic glutamate receptors. Activation of these receptors can generate retrograde signals, such as $\mathrm{NO}$ and cannabinoids, that act on the terminals of the presynaptic neurons and alter GABA release (Maejima et al., 2001; Robbe et al., 2002; Chevaleyre and Castillo, 2003; Nugent et al., 2007). There is also evidence that the activation of presynaptic NMDA receptors, when coincident with high-level GABAergic activity, is required for the induction of presynaptic LTD in the developing Xenopus retinotectal system (Lien et al., 2006). Several lines of evidence suggest that activation of presynaptic NMDARs is required for the induction of I-LTP in stellate cells. First, NMDAR blockers prevented the PF stimulation-induced increase in both spontaneous and evoked GABA release. Second, direct activation of NMDARs by a brief application of NMDA and glycine triggered I-LTP. Thus, activation of NMDARs is necessary and sufficient to induce a lasting increase in GABA release from stellate cells. Third, the induction of I-LTP appears to be independent of metabotropic glutamate receptors, NO, cannabinoid receptors, and $\beta$-adrenergic receptors. Fourth, NMDA/glycine application induced I-LTP that was not affected by BAPTA in the postsynaptic stellate cells, but was abolished in a Ca-free extracellular solution. This suggests that Ca entry into presynaptic neurons is required for the induction of I-LTP (Liu and Lachamp, 2006). Thus, presynaptic NMDA receptors may serve as a sensor for parallel fiber activity, and the resulting glutamate spillover triggers intracellular signaling in the presynaptic terminal, leading to a sustained alteration in the release of an inhibitory transmitter. The site of I-LTP expression is presynaptic and therefore differs from the rebound potentiation of inhibitory transmission observed in Purkinje cells after climbing fiber stimulation, which appears to be mediated postsynaptically (Kano et al., 1992). This glutamate-induced change in inhibitory transmission that we have observed could alter the balance between excitatory and inhibitory inputs or fine-tune the activity of neuronal networks within the cerebellum.

RIM1 $\alpha$, a presynaptic active zone protein, interacts with a 
number of presynaptic proteins, including Rab3a, which binds to synaptic vesicles, $\mathrm{Ca}^{2+}$ channels, synaptotagmin, and Munc 13 (for review, see Kaeser and Südhof, 2005). As the main RIM isoform expressed in the CNS, RIM1 $\alpha$ is present in many excitatory and inhibitory terminals. Studies of the function of RIM $1 \alpha$ have revealed diverse roles in transmitter release. Genetic deletion of RIM $1 \alpha$ enhances glutamate release at the Schaffer collateral-CA1 synapse, but reduces GABA release at the stratum radiatum interneuron-CA1 synapse (Schoch et al., 2002). In contrast, basal synaptic transmission and short-term plasticity at hippocampal mossy fiber synapses, cerebellar parallel fiber-toPurkinje cell synapses, and inhibitory synapses between stellate cells are not altered in RIM $1 \alpha$ knock-out mice (Castillo et al., 2002; Lonart et al., 2003; this study). At these synapses, RIM1 $\alpha$ has been shown to play a pivotal role in activity-induced lasting changes in transmitter release, including both presynaptic LTP and LTD. Deletion of RIM1 $\alpha$ abolishes presynaptic LTP at the hippocampal mossy fiber and cerebellar parallel fiber synapses, but enhances mossy fiber LTD (Castillo et al., 2002; Lonart et al., 2003). A recent study showed that cannabinoid-mediated LTD at inhibitory synapses in hippocampal CA1 neurons and in the basolateral amygdala requires the presence of RIM1 $\alpha$ (Chevaleyre et al., 2007). In the present study, we found that RIM1 $\alpha$ was also necessary for the NMDAR-induced I-LTP observed at inhibitory synapses between cerebellar stellate cells. Therefore, RIM1 $\alpha$ plays a central role in long-term modulation of both excitatory and inhibitory transmitter release. Although the stimulus that induces presynaptic plasticity varies at these different synapses, the same signaling pathway involving a cAMP-PKA-RIM $1 \alpha$ cascade seems to be involved. Thus, this pathway is a general mechanism for presynaptic plasticity in the CNS.

How does RIM1 $\alpha$ regulate neurotransmitter release during long-term synaptic plasticity? Deletion of RIM1 $\alpha$ reduces the readily releasable pool of synaptic vesicles (Calakos et al., 2004), whereas upregulation of RIM $1 \alpha$ enhances release probability (Yao et al., 2007). A recent study revealed that RIM1 suppressed the inactivation of voltage-gated calcium channels via its association with the $\beta$ subunits of calcium channels (Kiyonaka et al., 2007). Thus, RIM1 may enhance neurotransmitter release through its association with presynaptic proteins that facilitate vesicle docking or by controlling $\mathrm{Ca}^{2+}$ influx. One common feature of presynaptic LTP/LTD is the requirement for activation of PKA (Weisskopf et al., 1994; Salin et al., 1996; Storm et al., 1998; Tzounopoulos et al., 1998; Villacres et al., 1998; Linden and Ahn, 1999; Lonart et al., 2003; Chevaleyre et al., 2007). RIM1 $\alpha$ is a substrate for PKA and phosphorylation of RIM1 $\alpha$ at $\operatorname{Ser}^{413}$ is essential for presynaptic LTP (Lonart et al., 1998, 2003). RIM1 $\alpha$ interacts with Rab3a on the vesicular membrane, and this regulates synaptic vesicle fusion (Geppert et al., 1997; Schlüter et al., 2004). Although Rab3a itself is not a substrate for PKA, presynaptic LTP at hippocampal mossy fiber synapses is impaired in the Rab3a-deficient mouse (Castillo et al., 1997). Thus, signaling via Rab3a, perhaps though its interactions with $\operatorname{RIM} 1 \alpha$, is required for presynaptic LTP.

What are the functional consequences of the long-lasting change in inhibitory transmission that we have described? First, enhanced feedforward inhibitory (stellate cell) and excitatory $(\mathrm{PF})$ transmission in the cerebellar cortex enables Purkinje cells to integrate excitatory inputs with a high temporal fidelity (Scelfo et al., 2008). Thus, inhibitory transmission is required to maintain temporal resolution within the cerebellar network. Second, because stellate cells also innervate each other, an increase in GABA release is likely to addi- tionally alter the interneuron network activity. Chavas and Marty (2003) found that the reversal potential of GABAergic currents in stellate cells is $-58 \mathrm{mV}$ at room temperature and that both excitatory and inhibitory GABA synapses coexist in the cerebellar interneuron network. However, the reversal potential at a near-physiological temperature appears to be more hyperpolarized at approximately $-80 \mathrm{mV}$ (Carter and Regehr, 2002; Liu and Lachamp, 2006), and therefore GABAergic transmission is likely to be inhibitory. Indeed, our results show that enhanced GABA release from stellate cells reduces the spike rate and alters the pattern of action potential firing in nearby stellate cells, such that the postsynaptic cells fire in bursts. A change in the firing pattern of stellate/basket cells is likely to be influential because these neurons control the timing and firing frequency of Purkinje cells, which are themselves the sole output from the cerebellum (Midtgaard, 1992; Häusser and Clark, 1997; Jaeger and Bower, 1999). Finally, inhibitory networks participate in the generation of synchronized oscillations (Csicsvari et al., 1999; McBain and Fisahn, 2001; Buzsáki, 2002; Klausberger et al., 2003; Bartos et al., 2007; Middleton et al., 2008). Thus, a lasting increase in GABA release may be a general means to promote oscillatory activity within many types of neuronal networks.

\section{References}

Bartos M, Vida I, Jonas P (2007) Synaptic mechanisms of synchronized gamma oscillations in inhibitory interneuron networks. Nat Rev Neurosci 8:45-56.

Beaumont V, Zucker RS (2000) Enhancement of synaptic transmission by cyclic AMP modulation of presynaptic Ih channels. Nat Neurosci 3:133-141.

Beierlein M, Regehr WG (2006) Local interneurons regulate synaptic strength by retrograde release of endocannabinoids. J Neurosci 26:9935-9943.

Brown SP, Brenowitz SD, Regehr WG (2003) Brief presynaptic bursts evoke synapse-specific retrograde inhibition mediated by endogenous cannabinoids. Nat Neurosci 6:1048-1057.

Buzsáki G (2002) Theta oscillations in the hippocampus. Neuron 33:325-340.

Calakos N, Schoch S, Südhof TC, Malenka RC (2004) Multiple roles for the active zone protein RIMlalpha in late stages of neurotransmitter release. Neuron 42:889-896.

Carter AG, Regehr WG (2000) Prolonged synaptic currents and glutamate spillover at the parallel fiber to stellate cell synapse. J Neurosci 20:4423-4434.

Carter AG, Regehr WG (2002) Quantal events shape cerebellar interneuron firing. Nat Neurosci 5:1309-1318.

Castillo PE, Janz R, Südhof TC, Tzounopoulos T, Malenka RC, Nicoll RA (1997) Rab3A is essential for mossy fibre long-term potentiation in the hippocampus. Nature 388:590-593.

Castillo PE, Schoch S, Schmitz F, Südhof TC, Malenka RC (2002) RIMlalpha is required for presynaptic long-term potentiation. Nature 415:327-330.

Chadderton P, Margrie TW, Häusser M (2004) Integration of quanta in cerebellar granule cells during sensory processing. Nature 428:856-860.

Chavas J, Marty A (2003) Coexistence of excitatory and inhibitory GABA synapses in the cerebellar interneuron network. J Neurosci 23:2019-2031.

Chevaleyre V, Castillo PE (2003) Heterosynaptic LTD of hippocampal GABAergic synapses: a novel role of endocannabinoids in regulating excitability. Neuron 38:461-472.

Chevaleyre V, Heifets BD, Kaeser PS, Südhof TC, Purpura DP, Castillo PE (2007) Endocannabinoid-mediated long-term plasticity requires cAMP/ PKA signaling and RIM1alpha. Neuron 54:801-812.

Clark BA, Cull-Candy SG (2002) Activity-dependent recruitment of extrasynaptic NMDA receptor activation at an AMPA receptor-only synapse. J Neurosci 22:4428-4436.

Csicsvari J, Hirase H, Czurkó A, Mamiya A, Buzsáki G (1999) Oscillatory coupling of hippocampal pyramidal cells and interneurons in the behaving rat. J Neurosci 19:274-287. 
Duguid IC, Smart TG (2004) Retrograde activation of presynaptic NMDA receptors enhances GABA release at cerebellar interneuron-Purkinje cell synapses. Nat Neurosci 7:525-533.

Faber DS, Korn H (1991) Applicability of the coefficient of variation method for analyzing synaptic plasticity. Biophys J 60:1288-1294.

Fiszman ML, Barberis A, Lu C, Fu Z, Erdélyi F, Szabó G, Vicini S (2005) NMDA receptors increase the size of GABAergic terminals and enhance GABA release. J Neurosci 25:2024-2031.

Gaiarsa JL, Caillard O, Ben-Ari Y (2002) Long-term plasticity at GABAergic and glycinergic synapses: mechanisms and functional significance. Trends Neurosci 25:564-570.

Geppert M, Goda Y, Stevens CF, Südhof TC (1997) The small GTP-binding protein Rab3A regulates a late step in synaptic vesicle fusion. Nature 387:810-814.

Glitsch M, Marty A (1999) Presynaptic effects of NMDA in cerebellar purkinje cells and interneurons. J Neurosci 19:511-519.

Häusser M, Clark BA（1997） Tonic synaptic inhibition modulates neuronal output pattern and spatiotemporal synaptic integration. Neuron 19:665-678.

Jaeger D, Bower JM (1999) Synaptic control of spiking in cerebellar Purkinje cells: dynamic current clamp based on model conductances. J Neurosci 19:6090-6101.

Kaeser PS, Südhof TC (2005) RIM function in short- and long-term synaptic plasticity. Biochem Soc Trans 33:1345-1349.

Kano M, Rexhausen U, Dreessen J, Konnerth A (1992) Synaptic excitation produces a long-lasting rebound potentiation of inhibitory synaptic signals in cerebellar Purkinje cells. Nature 356:601-604.

Kiyonaka S, Wakamori M, Miki T, Uriu Y, Nonaka M, Bito H, Beedle AM, Mori E, Hara Y, De Waard M, Kanagawa M, Itakura M, Takahashi M, Campbell KP, Mori Y (2007) RIM1 confers sustained activity and neurotransmitter vesicle anchoring to presynaptic $\mathrm{Ca}^{2+}$ channels. Nat Neurosci 10:691-701.

Klausberger T, Magill PJ, Márton LF, Roberts JD, Cobden PM, Buzsáki G, Somogyi P (2003) Brain-state- and cell-type-specific firing of hippocampal interneurons in vivo. Nature 421:844-848.

Kondo S, Marty A (1998) Synaptic currents at individual connections among stellate cells in rat cerebellar slices. J Physiol 509:221-232.

Lien CC, Mu Y, Vargas-Caballero M, Poo MM (2006) Visual stimuliinduced LTD of GABAergic synapses mediated by presynaptic NMDA receptors. Nat Neurosci 9:372-380.

Linden DJ, Ahn S (1999) Activation of presynaptic cAMP-dependent protein kinase is required for induction of cerebellar long-term potentiation. J Neurosci 19:10221-10227.

Liu SJ, Cull-Candy SG (2005) Subunit interaction with PICK and GRIP controls $\mathrm{Ca}^{2+}$ permeability of AMPARs at cerebellar synapses. Nat Neurosci 8:768-775.

Liu SJ, Lachamp P (2006) The activation of excitatory glutamate receptors evokes a long-lasting increase in the release of GABA from cerebellar stellate cells. J Neurosci 26:9332-9339.

Liu SQ, Cull-Candy SG (2000) Synaptic activity at calcium-permeable AMPA receptors induces a switch in receptor subtype. Nature 405:454-458

Llano I, Gerschenfeld HM (1993) Inhibitory synaptic currents in stellate cells of rat cerebellar slices. J Physiol 468:177-200.

Lonart G (2002) RIM1: an edge for presynaptic plasticity. Trends Neurosci 25:329-332.

Lonart G, Janz R, Johnson KM, Südhof TC (1998) Mechanism of action of rab3A in mossy fiber LTP. Neuron 21:1141-1150.

Lonart G, Schoch S, Kaeser PS, Larkin CJ, Südhof TC, Linden DJ (2003) Phosphorylation of RIMlalpha by PKA triggers presynaptic long-term potentiation at cerebellar parallel fiber synapses. Cell 115:49-60.

Maejima T, Hashimoto K, Yoshida T, Aiba A, Kano M (2001) Presynaptic inhibition caused by retrograde signal from metabotropic glutamate to cannabinoid receptors. Neuron 31:463-475.

Maffei A, Nataraj K, Nelson SB, Turrigiano GG (2006) Potentiation of cortical inhibition by visual deprivation. Nature 443:81-84.

Mann-Metzer P, Yarom Y (1999) Electrotonic coupling interacts with intrinsic properties to generate synchronized activity in cerebellar networks of inhibitory interneurons. J Neurosci 19:3298-3306.

McBain CJ, Fisahn A (2001) Interneurons unbound. Nat Rev Neurosci 2:11-23.
Middleton SJ, Racca C, Cunningham MO, Traub RD, Monyer H, Knöpfel T, Schofield IS, Jenkins A, Whittington MA (2008) High-frequency network oscillations in cerebellar cortex. Neuron 58:763-774.

Midtgaard J (1992) Stellate cell inhibition of Purkinje cells in the turtle cerebellum in vitro. J Physiol 457:355-367.

Nugent FS, Penick EC, Kauer JA (2007) Opioids block long-term potentiation of inhibitory synapses. Nature 446:1086-1090.

Palay SL, Chan-Palay V (1974) Cerebellar cortex: cytology and organization. Berlin, Heidelberg, New York: Springer.

Paquet M, Smith Y (2000) Presynaptic NMDA receptor subunit immunoreactivity in GABAergic terminals in rat brain. J Comp Neurol 423:330-347.

Qiu DL, Knöpfel T (2007) An NMDA receptor/nitric oxide cascade in presynaptic parallel fiber-Purkinje neuron long-term potentiation. J Neurosci 27:3408-3415.

Rancillac A, Crépel F (2004) Synapses between parallel fibres and stellate cells express long-term changes in synaptic efficacy in rat cerebellum. J Physiol 554:707-720.

Robbe D, Kopf M, Remaury A, Bockaert J, Manzoni OJ (2002) Endogenous cannabinoids mediate long-term synaptic depression in the nucleus accumbens. Proc Natl Acad Sci U S A 99:8384-8388.

Saitow F, Suzuki H, Konishi S (2005) $\beta$-Adrenoceptor-mediated long-term upregulation of the release machinery at rat cerebellar GABAergic synapse. J Physiol 565:487-502.

Salin PA, Malenka RC, Nicoll RA (1996) Cyclic AMP mediates a presynaptic form of LTP at cerebellar parallel fiber synapses. Neuron 16:797-803.

Scelfo B, Sacchetti B, Strata P (2008) Learning-related long-term potentiation of inhibitory synapses in the cerebellar cortex. Proc Natl Acad Sci U S A 105:769-774.

Schlüter OM, Schmitz F, Jahn R, Rosenmund C, Südhof TC (2004) A complete genetic analysis of neuronal Rab3 function. J Neurosci 24:6629-6637.

Schoch S, Castillo PE, Jo T, Mukherjee K, Geppert M, Wang Y, Schmitz F, Malenka RC, Südhof TC (2002) RIMlalpha forms a protein scaffold for regulating neurotransmitter release at the active zone. Nature 415:321-326.

Shin JH, Linden DJ (2005) An NMDA receptor/nitric oxide cascade is involved in cerebellar LTD but is not localized to the parallel fiber terminal. J Neurophysiol 94:4281-4289.

Skeberdis VA, Chevaleyre V, Lau CG, Goldberg JH, Pettit DL, Suadicani SO, Lin Y, Bennett MV, Yuste R, Castillo PE, Zukin RS (2006) Protein kinase A regulates calcium permeability of NMDA receptors. Nat Neurosci 9:501-510.

Storm DR, Hansel C, Hacker B, Parent A, Linden DJ (1998) Impaired cerebellar long-term potentiation in type I adenylyl cyclase mutant mice. Neuron 20:1199-1210.

Sun L, Liu SJ (2007) Activation of extrasynaptic NMDA receptors induces a PKC-dependent switch in AMPA receptor subtypes in mouse cerebellar stellate cells. J Physiol 583:537-553.

Tzounopoulos T, Janz R, Südhof TC, Nicoll RA, Malenka RC (1998) A role for cAMP in long-term depression at hippocampal mossy fiber synapses. Neuron 21:837-845.

Villacres EC, Wong ST, Chavkin C, Storm DR (1998) Type I adenylyl cyclase mutant mice have impaired mossy fiber long-term potentiation. J Neurosci 18:3186-3194.

Weisskopf MG, Castillo PE, Zalutsky RA, Nicoll RA (1994) Mediation of hippocampal mossy fiber long-term potentiation by cyclic AMP. Science 265:1878-1882.

Yao I, Takagi H, Ageta H, Kahyo T, Sato S, Hatanaka K, Fukuda Y, Chiba T, Morone N, Yuasa S, Inokuchi K, Ohtsuka T, Macgregor GR, Tanaka K, Setou M (2007) SCRAPPER-dependent ubiquitination of active zone protein RIM1 regulates synaptic vesicle release. Cell 130:943-957.

Yoshida T, Hashimoto K, Zimmer A, Maejima T, Araishi K, Kano M (2002) The cannabinoid CB1 receptor mediates retrograde signals for depolarization-induced suppression of inhibition in cerebellar Purkinje cells. J Neurosci 22:1690-1697.

Zhong N, Zucker RS (2005) cAMP acts on exchange protein activated by cAMP/cAMP-regulated guanine nucleotide exchange protein to regulate transmitter release at the crayfish neuromuscular junction. J Neurosci $25: 208-214$. 